\title{
The Aesthetic Experience of Live Concerts: Self-Reports and Psychophysiology
}

\author{
Julia Merrill $^{1,2}$; Anna Czepiel $^{1}$; Lea Fink ${ }^{1}$; Jutta Toelle ${ }^{3}$; Melanie Wald-Fuhrmann ${ }^{1}$ \\ ${ }^{1}$ Max Planck Institute for Empirical Aesthetics, Frankfurt am Main, Germany \\ ${ }^{2}$ Institute of Music, University of Kassel, Kassel, Germany \\ ${ }^{3}$ Gustav Mahler Privatuniversität für Musik, Klagenfurt, Austria
}

\begin{abstract}
Author Note
Julia Merrill https:///orcid.org/0000-0001-9436-5219

All experimental procedures were approved by the Ethics Council of the Max Planck
\end{abstract} Society, and were undertaken with written informed consent of each participant. The data supporting the findings of this study are available from the corresponding author upon request. We declare that there are no conflicts of interest. We wish to thank Alexander Lindau, Patrick Ulrich and Eike Walkenhorst for help in organizing and implementing the concerts, Mathias Scharinger and Cornelius Abel for help with data preprocessing, Alessandro Tavano for data quality checks, Helen Singer for annotating the musical beats in the music recordings, and Thijs Vroegh and Elke Lange for the use of their absorption questionnaire. We thank Martin Tröndle and Folkert Uhde for preliminary ideas for this research project and the concert program. We thank Claudia Lehr and Freya Materne for organizing the invitations of the participants, and finally, thanks to the many assistants during data collection, particularly Till Gerneth, Sandro Wiesmann, Nancy Schön, and Simone Franz.

Correspondence concerning this article should be addressed to Julia Merrill, Max Planck Institute for Empirical Aesthetics, Grüneburgweg 14, 60322 Frankfurt am Main, Germany. Email: julia.merrill@ae.mpg.de 


\begin{abstract}
Music listening can lead to strong aesthetic experiences. However, to gain deeper insights into such experiences, more empirical research outside of laboratory settings is required. The current exploratory study measured aesthetic experience (music-induced emotions and absorption) in combination with psychophysiology (facial electromyography and arousal measures) from 98 participants during three live concerts with a program of classical, romantic, and contemporary chamber music. One musical movement from the contemporary work was presented from a recording. Results firstly highlight two key components of the concert frame as influencing the aesthetic experience: a) the programming order led to a riseand-fall trajectory of emotions with the less familiar contemporary work leading to higher negatively valenced emotions. Nonetheless, this experience was embedded in an overall highly appreciated concert, with b) the factor of liveness becoming apparent in lower engagement with the recorded than the live music. Secondly, the participants' reactions gave insights into how the multi-movement works were perceived; opening and closing movements elicited higher positively valenced arousal, contrasting the characteristics of an inner section, which evoked lower arousal and mixed emotions. This scheme differed between the classical and the romantic works in the third movements, reflecting a different trajectory of tension and relaxation in the respective styles. Finally, we show relations between physiological responses and self-reports reflecting both positive and negative aesthetic experiences. Overall, we demonstrate that the ecological validity of the current study is particularly informative for theoretical approaches on the aesthetic experience, with the frame as a crucial component. Keywords: live music, aesthetic emotions, absorption, concert research
\end{abstract}




\section{The Aesthetic Experience of Live Concerts: Self-Reports and Psychophysiology}

Music listening can lead to strong aesthetic experiences (Panzarella, 1980;

Gabrielsson, 2011). Whilst current frameworks of aesthetic experiences and emotions in music exist (Brattico et al., 2013; Brattico \& Pearce, 2013; Hargreaves \& North, 2013; Juslin, 2013), there is still a question of ecological validity in terms of stimuli and listening situations. So far, studies have typically been conducted in highly controlled laboratory environments, using only short musical works or excerpts (single movements or short clips). While such research may provide a good basis for understanding fundamental relationships between acoustic and musical characteristics, self-reports, and physiological responses, it is far from naturalistic forms and situations of music listening. In particular, typical lab approaches often do not include entire (multi-movement) pieces nor capture the supposedly crucial influence of the frame (Goffman, 1974) in which listening happens, despite situation and context being theoretically acknowledged as a key component in models of a visual aesthetic experience in art (e.g., Leder et al., 2004; Locher et al., 2016; Pelowski et al., 2016) and in the reciprocal feedback model in music (Hargreaves et al., 2005). In real life, the frame co-determines (among others) the intended function of the music, the works that are selected in order to achieve this function, the adopted listening mode (e.g., attentive or not) or what other behaviors are deemed appropriate in response to the music (Schäfer \& Sedlmeier, 2009; Greb, Steffens, \& Schlotz, 2018). Therefore, the current study aimed to explore the aesthetic experience of music listening in a real-world setting, namely in response to live performances of music in a concert hall including three string quintets by Ludwig van Beethoven, Johannes Brahms, and the contemporary composer Brett Dean.

\section{The Concert Frame: Attentive Listening in a Set Course}

To describe the relationship between situational factors and music-related behaviors, we adopt a term introduced by the sociologist Erving Goffman, i.e., the frame (Goffman, 1974). According to Goffman, frames contain components that are used by participants to 
understand, interpret, and evaluate the present situation and to align their behavior accordingly. Therefore, these frame components can be expected to also influence aesthetic experience and appreciation. Recently, studies have started to acknowledge the influence of the context, situation, or frame by moving into real-world settings such as theatres (Ardizzi et al., 2020), movie theatres (Kostoulas et al., 2015), art museums (Pelowski et al., 2012; Pelowski et al., 2017; Tschacher et al., 2012), and live music venues (e.g., Baltes \& Miu et al., 2014; Coutinho \& Scherer, 2017; Egermann et al., 2013; 2020 Scherer et al., 2018). A classical concert, which is the highly ritualized product of social conventions and stylistic development of Western music (Heister, 1988; Hewett 2017), contains several relevant frame components. These include the programming (deliberately choosing popular/famous works from the classical canon and perhaps a less well known piece (Gilmore, 1993; Weber, 2003)), the multimodal nature of the event (one cannot only hear the music live, but also watch the musicians creating it in the moment), and the setting aimed at affording an undisturbed, attentive, even absorbed mode of listening (created by the typical concert-hall layout with seats facing a lit stage, optimal acoustics, and learned behavioral regimes that call for silent and still listening) (Heister, 1988; Small, 1998; Seibert, Toelle, \& Wald-Fuhrmann 2020; Thorau \& Ziemer, 2019). Accordingly, the concert frame signals to the audience that the works to be heard are of high artistic value, and that they therefore should be received with attention because they promise the listener a special experience. Indeed, studies have shown that certain concert components enhance the music listening experience. Live performances of music tend to more frequently evoke strong (positive) responses (Gabrielsson \& Lindström Wik, 2003; Lamont, 2011). Additionally, a live performance in a church venue was shown to induce higher emotional engagement, and feelings of wonder and tenderness compared to a video recording of the same performance shown in a lecture hall (Coutinho, \& Scherer, 2017b). Attention has also been shown to be related to more intense, even absorbed experiences (Vroegh, 2018; Lange et al., 2017). Also, 
when asked about their motivation to go to concerts, attendees typically refer to their hope for deep and meaningful experiences (Brown \& Knox, 2016; Burland \& Pitts, 2014; Holt, 2010). Although studies have begun showing the effect of attentive listening during live opera performances (Baltes \& Miu, 2014; Scherer et al., 2018), no studies exist that explore the trajectory of an aesthetic experience with an intentional series of differing multi-movement works, which are a key component of classical concerts.

\section{The Compositional Strategy: A Music Theoretical Perspective}

While the concert frame determines the schematic nature of the concert on a global level, there is also the possibility to consider smaller units within the single compositions. To investigate these underlying compositional strategies in music, a music theoretical perspective can be taken on (Zbikowski, 2002). In a similar way to how linguistic research demonstrates that lower-level units group to higher-level structures - syllables group to words (with attentive listening, Ding et al., 2018), and words group to hierarchical sentence structures (Nelson, 2017) - such grouping is present also in music (for a review, see Patel, 2001) and systematic music theoretical methods further suggest categories to describe longer-term musical features. These longer-term features - such as themes and phrases which create sections - eventually constitute movements (i.e., separate parts in multi-movement works such as sonatas or symphonies). These categories are not only mere descriptions of the musical score, but have assigned functions that they fulfill for the listener within a given style (Caplin, 1998). Like the concert as such, compositions also follow certain trajectories which are typical for their respective style and genre.

Those familiar with European music between the $18^{\text {th }}$ and the early $20^{\text {th }}$ century (the so-called common practice period) in general have heard a comparable array of music which follow a similar compositional strategy - many times; to the extent that an expectation of how a (full-length) work and its movements may sound is developed. This is the basic assumption of a theory on one of the most influential and discussed forms in classical music: 
the sonata form (Hepokoski \& Darcy, 2006). Themes and movements are presented in a predefined order and harmonic schema, following specific functions by raising or denying expectations to create a higher-level form. This convention is typically used in symphonies and sonatas as well as chamber music genres of the (Viennese) classical and romantic period, which are represented in the current study through Ludwig van Beethoven and Johannes Brahms works, respectively. The traditional sonata cycle follows a standard four-movement pattern, with different tempi for each movement (fast - slow - dancelike - fast) as well as a development of key areas and the resulting harmonic expectancy (tonic - non-tonic - tonic tonic). Fast opening and closing movements frame two inner movements of a contrasting slow, song-like character, and a rhythmically pronounced dance-like character in triple meter (a Minuet or Scherzo). The aggregation of these movements has recently been described as the pairwise grouping of two movements towards a balanced symmetry of $2+2$ (Hepokoski \& Darcy, 2006, p. 338). However, empirical evidence whether this grouping is actually perceived by listeners or only part of a theoretical layout is still pending.

Although listeners implicitly gain knowledge through exposure (Bigand \& PoulinCharronnat, 2006) and have implicit knowledge of tonal music (e.g., Koelsch et al., 2000; Tramo et al., 2001) - at least on a local phrase level - psychological research does not seem to provide perceptual evidence for such high-level features of musical form. Concerning whole sections, studies have shown that aesthetic pleasure does not change when the intended order of form parts was not always in place, i.e., comparing stimuli in original versus manipulated forms (Cook, 1987; Gotlieb \& Konečni, 1987; Karno \& Konečni, 1992). However, emotional characteristics and physiology related to the formal functions of whole movements from different musical styles has not been investigated.

In our concert, two instantiations of a sonata cycle (Beethoven and Brahms, both four movements) were contrasted by the four sequential movements of a "suite" (Dean, contemporary work). This allowed for investigating audience's responses to the formal 
structure of two different four-movement patterns: the cyclic organization of the sonata form and the sequential order of the suite.

\section{Measuring the Aesthetic Experience}

Although there are several dimensions that can encompass an aesthetic experience, we chose to focus on two components that have been previously identified as key components of an aesthetic experience with music (Brattico et al., 2013; Brattico \& Pearce, 2013), that is music-evoked emotions and absorption.

The importance of absorption in the aesthetic discourse about classical music has been discussed in music history literature (Herbert 2011; Hoffding, 2018). Conceptualizing the aesthetic experience as a distinctive state of mind (Levinson, 2003, p. 7; Vroegh, 2018) that is related to the focused perception of sensory objects and differs from 'everyday' mental states, the state of absorption presents itself as a valuable measure for the aesthetic experience of music in a concert, where parameters are traditionally designed to optimize focus only on the music. These parameters include dimmed lights, an engineered room architecture for optimum acoustics (which influence perceived clarity of melodic lines, loudness and reverberation; Lokki et al., 2012; Lokki et al., 2011), as well as behavioral conventions of attentive listening such as (expected) total silence, and sitting still (Heister, 1983).

Emotions have also been shown to be part of aesthetic experience (Brattico et al., 2013; Brattico \& Pearce, 2013; Menninghaus et al., 2019; Schindler et al., 2017). It is worth noting here the differentiation between perceived and felt emotions (Gabrielson, 2001; Schubert, 2013). While works of classical music are expected to have an expressive component and to be performed expressively, they do not necessarily evoke the same emotions that they might express, nor are they expected to (e.g., music may evoke mixed emotions such as being moved, Trost et al., 2012). Recent research has led to more standardized self-report tools to measure such evoked emotions, with some constructed to be applicable to art and non-art (e.g., nature) domains, such as AESTHEMOS (Schindler et al., 
2017), or shorter tools that apply to more specific domains such as classical music (GEMIAC, Coutinho \& Scherer, 2017a).

In addition to self-reports, a non-obtrusive and continuous method to measure experienced emotions is using electromyography (EMG), cardiovascular and respiratory measures, and skin conductance (see Cacioppo, Berntson, Larsen, Poehlmann, \& Ito, 2000). Responses such as increased sweat gland secretion (measured by skin conductance), heart and respiration rate - activated by the sympathetic division of the autonomic nervous system in response to stimulating events - reflect increased felt arousal and engagement (Benedek \& Kaernbach, 2010; Bradley \& Lang, 2000; Cacioppo et al., 2000). Facial muscle activity is also considered a measure of behavior (Cacioppo et al., 2000) and can reflect mimicry of several discrete emotions (Wingenbach, 2020), and - to a certain extent - evoked emotions, e.g., the zygomaticus major (smiling) muscle and corrugator supercilii (frowning) muscle have been shown to reflect positive and negative valence, respectively (Bradley \& Lang, 2000).

Most research on physiology and emotions during music listening concerns how the perceived emotion of the music is reflected in felt emotions, i.e., the emotion of the music is induced within the listener. Studies using either categorical (e.g., happy, sad) or dimensional (valence-arousal) emotion concepts show that 'happy' or arousing music (rated as inducing happiness or high arousal in listeners) evoked higher skin conductance amplitudes, faster breathing and heart rates compared to sad or music with low arousal (happy vs. sad: Etzel et al., 2006; Khalfa et al., 2002; Khalfa et al., 2008; Krumhansl, 1997; Lundqvist et al., 2009; high vs. low arousal: Egermann et al., 2015; Egermann et al., 2013; Gomez \& Danuser, 2004). Higher smiling muscle activity was also associated with happy compared to sad music (Khalfa et al., 2008; Lundqvist et al., 2009).

Other research demonstrate how physiology may reflect emotions above and beyond the emotion of the music itself, such as pleasure, aesthetic chills, or perceived beauty. Music 
rated as pleasurable, or reported as evoking chills during music listening, evoked higher skin conductance amplitudes, faster breathing and heart rates (pleasure: Salimpoor et al., 2009; Sammler et al., 2007; chills: Blood \& Zatorre, 2001; Craig, 2005; Guhn et al., 2007; Rickard, 2004; Roy et al., 2009; Salimpoor et al, 2009). Pleasant music also reduces certain motor activity such as eye blink amplitude (Roy et al., 2009). Additionally, heart rate is found to be higher during music judged as 'beautiful' (though this effect is dependent on speed; de Jong et al., 1973). More recently, Omigie et al. (2019) found an interaction between the music judged as beautiful and its induced emotions: higher skin conductance was found in high energy beautiful music, whereas more smiling and higher respiration rate were associated with low tension and low energy beautiful music. However, there is limit on studies that show which kind of physiology may reflect more negative aesthetic experiences. Particularly in a live music situation, where full pieces of music are presented, one can expect a variety of music-evoked emotions.

\section{The Present Investigation}

This current study considers specific concert features and full-length musical trajectories of differing genres as an important element to influence effects on aesthetic experiences (here measured using behavioral responses and psychophysiological measures), thus making our approaches and hypotheses rather exploratory. To investigate the aesthetic experience of music in a real-world (as opposed to laboratory) situation, the current study tested 98 participants across three identical live concert evenings. The concert program comprised three string quintets in classical, romantic, and contemporary style with four movements each. Participants were asked to fill out short questionnaires on their aesthetic experiences, i.e., music-induced emotions (GEMIAC, Coutinho \& Scherer, 2017a) and absorption (Vroegh, 2018) which were reported after each movement. Physiology was continuously measured throughout the whole concert. 
Despite the exploratory nature of this ecological set-up, we nonetheless had a few hypotheses. We expected to (1) see how behavior and physiology may reflect the concert frame, e.g., its programming in form of differences between the classical, contemporary, and romantic works. We also expected to (2) observe compositional strategies of the works mirroring in audience responses, i.e., differences between movements due to their functions within a sonata cycle or suite. By choosing full pieces of music that were able to elicit an aesthetic experience on various levels - rather than choosing music that reflect one specific emotion (e.g., Khalfa et al., 2002; 2008) or that evokes primarily pleasurable emotions (e.g., Omigie et al., 2019; Salimpoor et al., 2009) - we additionally hoped to (3) extend typical laboratory studies on the relations between physiology and a wider range of positive and negative aesthetic experiences. This study will widen our knowledge on how people experience music aesthetically and emotionally based on self-reports and psychophysiology in the real-world setting of a live concert.

\section{Methods}

\section{Venue}

The ArtLab is a special concert hall designed for empirical investigations. It comprises 46 comfortable seats with arm rests and a pull-out table, arranged in five rows. The room is engineered to ensure equal sound quality for all seats. It has a stage, sound system with speakers, microphones and video cameras on the ceiling. In front of the ArtLab is a large foyer, where participants were prepared for physiological data acquisition.

\section{Participants}

46 different participants responded a public advertisement for a chamber music concert for each of the three concerts. Some participant data were lost due to technical issues of server and user failures or data loss $(N=31)$. A resulting number of 98 physiology data 
sets (Concert $1(\mathrm{C} 1), N=36$; Concert $2(\mathrm{C} 2), N=41$; Concert $3(\mathrm{C} 3), N=21)$ and 88 complete data sets (physiology and self-report data) were used for final analyses.

The gender distribution was similar across concerts $(\mathrm{C} 1=15 / 17$ female/male, $\mathrm{C} 2=$ 16/17, C3 =9/12; 3 not stated). Age groups across concerts were also quite similarly distributed: participants were asked to choose their age group (within a five-year range, i.e., 18-22, 23-27, ... 95-99), where half of the participants in $\mathrm{C} 1$ marked their age as being between 18-50, in $\mathrm{C} 2$ between 18-55 and C3 between 18-40 years old. Most participants in all three concerts indicated their highest education level was a university degree $(N=23,25,17)$, a high school degree with German "Abitur" $(N=8,5,4)$ or a finished vocational/professional training (without "Abitur"; $N=1,4,0)$.

To evaluate musical sophistication, two sub-scales from the German version of The Goldsmiths Musical Sophistication Index (Gold-MSI, Schaal et al., 2014) were chosen: General Music Sophistication and Emotional Engagement with Music (Müllensiefen et al., 2014). The participants across the three concerts were very similar a) for the overall sophistication: $\mathrm{C} 1(\operatorname{mean}(M)=69.84, S D=22.01), \mathrm{C} 2(M=71.61, S D=21.97), \mathrm{C} 3(M=$ $70.76, S D=19.33)$ and b) for the emotion scale: $\mathrm{C} 1(M=33.53, S D=4.75), \mathrm{C} 2(M=31.17$, $S D=6.85), \mathrm{C} 3(M=33.24, S D=5.45)$.

Participants reported that they most often visit concerts comprising of classical music and opera. Half of the participants came to the concert with someone else (see supplemental material for details).

\section{Materials}

The chosen repertoire for the live performances of a string quintet was based on an artistic decision by musicologists and curators, reflecting the stylistic variety and order (including an interval) typical of present-day classical chamber music concert programming. The first string quintet played was from the Classical period, op. 104 in C minor (1817) by Ludwig van Beethoven, with four movements. From the second work, "Epitaphs" (2010) by 
the contemporary composer Brett Dean, also four movements were presented - the fifth one was omitted for artistic reasons. The third work was from the Romantic period: the string quintet op. 111 in G major (1890) by Johannes Brahms, also comprising four movements.

The contemporary work by Dean is written as a suite with five movements, each of them musically independent from each other, and each paying homage to personal friends. This work generally has more complex/dissonant harmonic and rhythmic structures. Each movement emphasizes a characteristic set of acoustic features (Figure 1), some of them more challenging to the standard listening experience than others. For instance, timbre and intonation of the performance of the first movement - resulting from the realization of various harmonics in the score - can be described as more challenging to listen to than the more consonant and melodic third movement. The last (fourth) movement played in the concert has the character of a typical finale in terms of clear, engaging rhythm, and repetitive structures. Even though there is no standard musical form to label the overall work, there is a clear dramaturgical development from movement one to movement four, which closes with an effectual ending.

Beethoven's and Brahms' quintets are exemplars of the traditional sonata cycle (Hepokoski \& Darcy, 2006), following the standard four-movement pattern as described above (Figure 1).

--- Figure 1 about here ---

The performing musicians were a string quintet from the Frankfurt am Main (Germany) area, working solely as professional orchestra and chamber musicians. The musicians were accordingly compensated for their time playing in all three concerts. As the main aim was to keep the three performances as comparable as possible, the musicians were instructed to achieve similarity across concerts, which was more likely to be ensured with a professional group of musicians that regularly play together. 
The second movement of the work by Dean "II. Walk a little way with me" was presented as recording (Doric String Quartet, Brett Dean Viola, Chandos, 2015) via loudspeaker (with musicians still sitting on stage). The idea behind this decision was to have one stimulus presentation with the exact same acoustic properties across all three concerts and without the visual aspects and the live acoustics, which are (besides the frame) typical characteristics of laboratory situations. As one of the main aims of the study was to keep the setting as naturalistic as possible, it seemed most plausible for the concert to have the control comparison recording in the contemporary work - as this style typically can also include electro-acoustic elements - rather than in the classical work or the romantic work (which may lead to confusion if a recording of only one of the movements was played throughout a classical or romantic work).

\section{Procedure}

Participants were invited to arrive at the venue one or one and a half hour(s) prior to the beginning of the concert. Firstly, participants were informed about the study and signed required agreements to take part in the study, they were also handed a program that included the composer's name, the work with year of composition, and the names of the movements (no further text was presented). They were then prepared for the physiological recording, which included the measurement of the (a) zygomaticus major (smiling) muscle activity measured by EMG with adhesive electrodes on the left side of the face (with a ground electrode placed on the mastoid), (b) respiration rate (RR), measured using a custom prepared respiration belt wrapped around the lower rib cage, (c) electrodermal activity (EDA) was measured with electrodes attached to the index and middle fingers of the non-dominant hand - from which phasic skin conductance (SC) could be inferred - as well as (d) blood volume pulse (BPV) measured with a plethysmograph clip - from which heart rate (HR) could be inferred. Electrodes were connected to a portable amplifier, the "biosignalsplux" system (https://plux.info/12-biosignalsplux; "plux" herafter). The plux device recorded the data from 
the incoming sensors and was attached with adhesive tape to the participants upper back, and remained there for the entirety of the concert. Data were sampled at a $1000 \mathrm{~Hz}$ rate. Concerts started at 7:30 p.m. Beethoven and Dean were performed in the first half; Brahms was performed in the second half. In between, a 20-minute break was taken outside the ArtLab concert hall foyer. Concerts ended approximately 9:45 p.m.

After each movement, a short break (roughly two minutes) was taken to fill out two short questionnaires on a tablet. The first questionnaire comprised eight items of state absorption taken from Vroegh (2018, p. 150 and p. 203) including liking, all evaluated on a 5point Likert scale from very much to not at all. The questionnaire comprised items on altered awareness, such as "I was completely absorbed by the music," "Time passed quickly," on dissociation, such as "I did not notice the surroundings," "I forgot being at a concert," attention, such as "I focused completely on the music," and control items, such as "My mind was wandering" and "I was totally bored." The second questionnaire on the next page comprised the 14 "emotion classes" from the GEMIAC (Coutinho \& Scherer, 2017a). This “checklist" contains a selection of affect and emotion categories, where each category was derived from a hierarchical cluster analysis, leading to so called emotion classes. Each class is represented by one item containing two terms: filled with wonder/amazed, moved/touched, enchanted/in awe, inspired/enthusiastic, energetic/lively, joyful/wanting to dance, powerful/strong, full of tenderness/warmhearted, relaxed/peaceful, melancholic/sad, nostalgic/sentimental, indifferent/bored, tense/uneasy, agitated/aggressive. The items were translated into German by taking the adjectives from a comparable assessment, AESTHEMOS (Schindler et al. 2017), and the intensity of each emotion as felt by participants were assessed on a 5-point Likert scale.

Additional questions were presented after each work and after the concert, for example on familiarity with this kind of music (options of: "Yes," "No," and "I am not sure"; see supplemental material). Participants were compensated with a free ticket to the concert, 
including a complementary non-alcoholic/-caffeine refreshment during the interval. They did not receive any further monetary compensation.

The three concerts were conducted on three consecutive evenings. In order to have the concerts as comparable as possible, great care was taken to ensure factors of timing, performers, lighting, and temperature, which were kept the same across these three concerts.

\section{Analysis of Physiological Measures}

All signal processing was carried out using custom scripts written in MATLAB 2018b (The MathWorks). Plux data were transformed from raw to meaningful measures following the data sheets provided by the developer, i.e., EMG and BVP in millivolt, EDA in microSiemens, and respiration in percentage of displacement. Missing data (gaps of less than 50ms) were interpolated at the original sample rate.

\section{Electromyography}

To obtain a continuous measure of facial muscle activity over time, the EMG was band-pass filtered between 90 and $130 \mathrm{~Hz}$, and the absolute value of the Hilbert transform of the filtered signal was extracted and then smoothed using the conv2 function in MATLAB, as recommended (http://www.fieldtriptoolbox.org/documentation; Oostenveld et al., 2011).

\section{Respiration and Heart Rate}

The respiration signal was low-pass filtered by $0.6 \mathrm{~Hz}$ and demeaned. BVP signal was band-pass filtered between 0.8 and $20 \mathrm{~Hz}$, and demeaned. For both signals, peaks in the raw signal were identified using a function that identified local minima and maxima in any given epoch, visual inspection was used to confirm that peaks were correctly identified. Finally, rate for each signal was estimated by taking a differential of the timings of maxima (inter-beat intervals) and the resulting rate time-series were interpolated to a regular sampling frequency to give continuous HR and RR. Data were kept at $1000 \mathrm{~Hz}$ sampling rate. Noisy HR data were additionally identified using Poincaré plots (Mourot et al., 2004a, Sosnowski et al., 
2005) and single work movements by single participants were excluded if more than $10 \%$ of data were affected.

\section{Skin Conductance}

EDA was down sampled to $20 \mathrm{~Hz}$ and analyzed by means of Discrete Decomposition Analysis (CDA) from the Ledalab toolbox (Benedek \& Kaernbach, 2010) performing optimization of four initial values and data smoothing using the gauss-method and a window width of 16 samples. This resulted in a mean amplitude of phasic skin conductance components (SC), which reacts in an event-related manner.

\section{Measures}

In order to get meaningful measures despite varying movement lengths, number of events per minute were used, in addition to mean rate and amplitude. For SC, the mean amplitude of phasic activity and number of events per minute were calculated; however, the number of events did not follow a normal distribution, so only the mean amplitude of phasic activity was taken for further analysis. For the EMG signal, mean amplitude did not give a meaningful measure, as the amplitude averaged out too much (most likely as the time across each movement was several minutes, as opposed to typical trials lasting a few seconds), so the number of events per minute was used instead. An event was defined by moments when the signal was higher than a threshold (the individual mean plus two times the standard deviation was used, i.e., being the threshold for a $p<.05$ value following a normal Gaussian distribution). For HR and RR, the mean per movement was calculated. This yielded in 4 physiological data points per participant per movement: mean HR (beats per minute, BPM), mean RR (breaths per minute), mean amplitude of phasic skin conductance, and mean number of EMG events per minute, although after manual data checks some participants HR and / or SC data was rejected, so some participants only had two or three physiological data points. In total, 98 data sets were used for EMG and RR, 88 for skin conductance, and 82 for HR data. 


\section{Acoustical Analysis}

To compare acoustic variability between the concerts, acoustic features representing performance-based features (i.e., features not describing the music composition itself, but rather acoustic features that may vary from performance to performance, Beveridge \& Knox, 2009; Goodchild et al., 2017) were obtained manually and computationally. Using the MIRToolbox (Lartillot \& Toiviainen, 2007), RMS (a feature typically representing loudness perception) and spectral centroid (the feature most commonly used to represent timbre, or 'brightness'; Alluri \& Toiviainen, 2011; Grey \& Gordon, 1978; Iverson \& Krumhansl, 1993; McAdams et al., 1995) were extracted in 25ms time windows as is typical in MIR analysis (Tzanetakis \& Cook, 2002). As a longer-term feature, tempo is not always successfully captured by computational methods (Lange \& Frieler, 2018), and was therefore extracted manually using Sonic Visualiser (Cannam et al., 2010), by tapping in timestamps for each beat of the performances of each movement (yielding a vector of timestamps per beat and bar), calculating the inter-onset intervals (IOIs) between beats, and converting these to beats per minute. Loudness, timbre, and tempo values were averaged in time windows per bar to allow comparisons between concerts.

\section{Statistical Analysis}

Statistical analyses were carried out using $R$ (R Core Team, 2014). All questionnaire items were recoded so that the highest number reflects highest intensity.

The lme4 package within $R$ (Bates et al., 2015) was used to construct linear mixed effects models (LMM). The significance of the fixed effects was tested with conditional $F$ tests using the anova function and the lmerTest package (Kuznetsova et al., 2017). Pairwise comparisons using the Tukey method were performed with the emmeans package (Lenth et al., 2018). Two (Pseudo-) $\mathrm{R}^{2}$ values (marginal and conditional) were calculated with the MuMin package (Bartoń, 2015), which is designed for general and linear mixed effects models. The randomForest package in $R$ (Liaw \& Wiener, 2002) was used to construct 
random forest regressions. 500 trees were fitted. The output gives the percent explained variance of each model and the importance of each variable in explaining the variance. The 'importance' of each predictor was indicated in \%IncMSE, which shows the increase in mean squared error of predictions as a result of a variable being permuted. Because random estimations depend upon the computer's random number generator, each model was replicated 100 times to examine the distribution of $\mathrm{R}^{2}$ oob as well as the variable importance across replications. For multiple and forest regressions, reference values for interpreting $\mathrm{R}^{2}{ }_{\text {GLMM }}$ and $\mathrm{R}_{\text {oob}}^{2}$, respectively, can be taken from Cohen (1988), that is a small effect $\mathrm{R}^{2}=$ .02 , medium effect $\mathrm{R}^{2}=.13$ and large effect $\mathrm{R}^{2}=.26$. All statistical results of fixed and random effects can be found in supplemental material.

\section{Acoustic Comparisons}

Performance acoustic features were correlated per movement between concerts using the corr.test function from psych package in R (Revelle, 2019), adjusted for false discovery rate. All acoustic correlations of instantaneous tempo, timbre, and loudness between concert 1 (C1), concert $2(\mathrm{C} 2)$ and concert $3(\mathrm{C} 3 ; \mathrm{C} 1-\mathrm{C} 2, \mathrm{C} 1-\mathrm{C} 3, \mathrm{C} 2-\mathrm{C} 3)$ had $r$ values above 0.6 , with $p$ $<.001$ (with most correlations at $r>0.8$ ), meeting the criteria for a large effect size in correlation of $r>0.5$ (Cohen's q for correlation coefficients, Cohen 1988). This confirms that the concerts were similar enough acoustically to allow further statistical analysis (i.e., that measured self-report and physiology across concerts were in response to a stimulus that remained comparable over the concerts). Unsurprisingly, apart from the (recorded) Dean $2^{\text {nd }}$ movement, most $r$ values were all under .95, suggesting that the performances differ slightly from each other, reflecting the 'live' aspect of performances: that even highly practiced performances offer slight deviations in interpretation to offer a fresher performance, as well as exhibiting small human errors (Chaffin et al., 2007; Palmer, 1997) 


\section{Reliability of the Questionnaires}

Intra-class correlation (two-way random effects model, type: consistency) was performed for the eight absorption items and revealed an average measure ICC of .535 with a $95 \%$ confidence interval from .491 to $.577(F(1020,7140)=2.151, p<.001)$. The ICC for the 14 emotion items from the GEMIAC revealed an average measure ICC of .734 with a $95 \%$ confidence interval from .709 to $.759(F(924,12012)=3.766, p<.001)$.

\section{Factor Analysis}

All items from the GEMIAC and the absorption scale were subjected to a factor analysis. The $f a$ function (also from the psych package) was used with direct oblimin rotation, after determining the number of factors performing a parallel analysis. Five factors (latent variables) were identified (Table 1).

\section{Table 1}

Factor structure of the items from the GEMIAC and the absorption scale

\begin{tabular}{|c|c|c|c|c|c|c|}
\hline Questionnaire & Items & $\begin{array}{l}\text { Positive } \\
\text { emotions }\end{array}$ & Engagement & $\begin{array}{l}\text { Negative } \\
\text { emotions }\end{array}$ & $\begin{array}{l}\text { Mixed } \\
\text { emotions }\end{array}$ & Dissociation \\
\hline & $\begin{array}{l}\text { Proportion of variance } \\
\text { explained }\end{array}$ & 0.29 & 0.22 & 0.19 & 0.18 & 0.12 \\
\hline GEMIAC & energetic/lively & 0.82 & & & & \\
\hline GEMIAC & powerful/strong & 0.69 & & & & \\
\hline GEMIAC & inspired/enthusiastic & 0.69 & & & & \\
\hline GEMIAC & joyful/wanting to dance & 0.66 & & & & \\
\hline GEMIAC & filled with wonder/amazed & 0.62 & & & & \\
\hline GEMIAC & enchanted/in awe & 0.51 & & & 0.36 & \\
\hline Absorption & bored & & -0.68 & & & \\
\hline GEMIAC & indifferent/bored & & -0.67 & & & \\
\hline Absorption & concentrated & & 0.58 & & & \\
\hline Absorption & forgetting time & & 0.55 & & & \\
\hline Absorption & absorbed & & 0.54 & & & 0.37 \\
\hline Absorption & liking & & 0.47 & -0.40 & & \\
\hline Absorption & mind wandering & & -0.31 & & & \\
\hline GEMIAC & tense/uneasy & & & 0.89 & & \\
\hline GEMIAC & agitated/aggressive & & & 0.84 & & \\
\hline GEMIAC & relaxed/peaceful & & & -0.43 & 0.41 & \\
\hline GEMIAC & nostalgic/sentimental & & & & 0.78 & \\
\hline GEMIAC & melancholic/sad & & & & 0.72 & \\
\hline GEMIAC & tenderness/warmhearted & 0.30 & & & 0.51 & \\
\hline GEMIAC & moved/touched & 0.42 & & & 0.46 & \\
\hline Absorption & forgetting being in a concert & & & & & 0.73 \\
\hline Absorption & forgetting surroundings & & & & & 0.70 \\
\hline
\end{tabular}

Note. Factor loadings $<.3$ are omitted. 


\section{Effects of Work and Movement on Emotion and Absorption Items}

To investigate effects of performances of different works and movements on the selfreports, LMMs were performed for each latent variable separately as the dependent variable, with the fixed effect of (a) Work (three works, with random intercept of Movement and Participant) or (b) Movement (12 movements, with random intercept of Participant).

\section{Effects of Concert, Work, and Movement on Psychophysiology}

To evaluate effects of concert, musical work, and movement on physiological measures, separate LMMs were fitted for each physiological measure with fixed effect of Concert (three concerts) or Work (three works with random intercept of Movement and Participant) or Movement (12 movements, with random intercept of Participant) separately.

\section{Effects of Emotion and Absorption Items on Psychophysiology}

Two approaches were chosen to investigate the relationships between ratings and physiological measures. Firstly, an exploratory approach using random forest regression was used to find the best predictors (based on importance values) within the self-reports for each psychophysiological measure. Random forests were fitted for each physiological measure with all rating items $(\mathrm{N}=22)$ as predictors. Secondly - because the results from random forest regressions do not give an objective threshold for importance values - LMMs were fitted for each physiological measure with the latent variables as fixed effects (four physiological measures, with random intercept of Participant). Because one absorption factor and one emotion factor correlated (factors positive emotions and dissociation; $r=.57$ ), we made two models to avoid issues with multicollinearity. One model entailed the emotion related factors (positive, negative, and mixed emotions as fixed effects), the other the absorption related factors (engagement and dissociation as fixed effects). 


\section{Results}

\section{Self-Reports}

Concert. Across all three concerts, participants liked the concert as a whole $(M=4.10$, $S D=0.69)$ as well as the atmosphere $(M=3.82, S D=0.83)$. They had the feeling they were actually visiting a concert (rather than being part of a study; $M=3.81, S D=1.01$ ), reporting low disturbance of the electrodes $(M=2.17, S D=1.0)$. Reported duration of preparation of physiological set-up before the concert $(M=3.98, S D=0.81)$, and of the concert itself $(M=$ 4.22, $S D=0.70$ ) was appropriate and participants could imagine visiting such a research concert again $(M=4.64, \mathrm{~S} D=0.64)$.

Works. The quintets by Brahms and Beethoven were familiar for the majority of participants (only 19\% and 29\% respectively reported they were not sure if they knew it), which was not the case for Dean's work (98\% reported not to know it). Mean liking ratings of the (whole) works were for Beethoven $M=4.09(S D=0.88)$, for Brahms $M=3.99(S D=$ $0.78)$, and Dean $M=3.25(S D=1.18)$.

\section{Differences Between Works and Movements in Self-Reports}

Effects of Work and Movement on each latent variable can be seen in the significant $F$ tests resulting from the linear mixed models in Table 2.

Works. Compared to Brahms and Beethoven, Dean's work received lowest ratings of positive emotions (marginally missing significance to Beethoven) and mixed emotions (significantly lower than Brahms), but highest ratings of negative emotions (significantly higher than both other works). Brahms' quintet was rated highest on dissociation (significantly higher than Dean). No significant differences were found between works for engagement (pairwise comparisons are depicted in Figure 2; all statistics can be found in supplemental material). 


\section{Table 2}

Results of the conditional F-tests following the linear mixed effects models for each latent variable and the fixed effects of Work or Movement

\begin{tabular}{|l|l|l|l|l|l|l|l|l|}
\hline & Work & & & & Movement & & & \\
\hline Latent variable & $F(2,9)$ & $p$ & $R^{2}(\mathrm{~m})$ & $R^{2}(\mathrm{c})$ & $F(11,815)$ & $p$ & $R^{2}(\mathrm{~m})$ & $R^{2}(\mathrm{c})$ \\
\hline Positive emotions & 3.781 & .064 & .058 & .454 & 19.261 & $<.001$ & .131 & .447 \\
\hline Mixed emotions & 6.075 & .021 & .153 & .589 & 53.013 & $<.001$ & .275 & .576 \\
\hline $\begin{array}{l}\text { Negative } \\
\text { emotions }\end{array}$ & 71.251 & $<.001$ & .339 & .552 & 65.421 & $<.001$ & .360 & .551 \\
\hline Engagement & 0.867 & .452 & .007 & .340 & 5.333 & $<.001$ & .043 & .338 \\
\hline Dissociation & 6.702 & .016 & .013 & .477 & 3.310 & $<.001$ & .021 & .479 \\
\hline
\end{tabular}

Movements. In positive emotions, a difference occurred between the second and the outer movements of the classical and the romantic works: Beethoven's $3^{\text {rd }}$ and $4^{\text {th }}$ movements had significantly higher ratings compared to the $2^{\text {nd }}$ movement. Brahms' $4^{\text {th }}$ movement had significantly higher ratings compared to the $1^{\text {st }}$ through $3^{\text {rd }}$ movements (Figure 2). For Dean, the $4^{\text {th }}$ movement had significantly higher ratings compared to the $1^{\text {st }}$ and the $2^{\text {nd }}$ in positive emotions.

In mixed emotions, a reversed pattern could be seen where Beethoven's and Brahms' $2^{\text {nd }}$ movements had significantly higher ratings compared to the $1^{\text {st }}, 3^{\text {rd }}$, and $4^{\text {th }}$ movements. For Dean, the $1^{\text {st }}$ movement had significantly higher ratings compared to the $4^{\text {th }}$ movement. In negative emotions, Dean's $1^{\text {st }}$ movement was significantly higher than the $4^{\text {th }}$. No significant differences within the Beethoven and Brahms movements were found.

In engagement, Beethoven's $3^{\text {rd }}$ movement was significantly higher than the $2^{\text {nd }}$, and Brahms' $4^{\text {th }}$ movement higher than the $1^{\text {st }}, 2^{\text {nd }}$, and $3^{\text {rd }}$, being the highest in the whole concert. Dean's $4^{\text {th }}$ movement was significantly higher than the $2^{\text {nd }}$. There were no significant differences between movements within works for dissociation. 
The part presented via loudspeaker, Dean's $2^{\text {nd }}$ movement, received lowest ratings in engagement, which was significantly lower compared to Dean's $4^{\text {th }}$, Beethoven's $3^{\text {rd }}$ and $4^{\text {th }}$ and Brahms' $4^{\text {th }}$ movement.

\section{Psychophysiological Measures}

\section{Differences Between Concerts, Works, and Movements}

Concert. LMMs with physiological measures as dependent variables and concert as independent variable revealed no differences between concerts (see supplemental material). Along with the very similar acoustic features across concerts, this confirms that the physiological data from three separate but comparable concerts do not differ significantly based on the mean values and can be treated as a single group. Therefore, no comparisons are made between concerts in the following analyses.

Works. The LMMs for Work show significant differences for SC, EMG, and HR response, but not for RR (Figure 3; Table 3). Dean received significantly higher physiological responses than Brahms for SC, HR, and EMG. Beethoven had significantly higher HR responses compared to Dean and Brahms.

--- Figure 3 about here ---

\section{Table 3}

Results of the conditional F-tests following the linear mixed effects models for each psychophysiological measure and the fixed effects of Work or Movement

\begin{tabular}{|l|l|l|l|l|l|l|l|l|l|l|l|}
\hline & Work & & & & & Movement & & & & \\
\hline Measure & $F$ & $\mathrm{df}$ & $p$ & $R^{2}(\mathrm{~m})$ & $R^{2}(\mathrm{c})$ & $F$ & $\mathrm{df}$ & $p$ & $R^{2}(\mathrm{~m})$ & $R^{2}(\mathrm{c})$ \\
\hline EMG & 5.54 & $2,8.99$ & .027 & .018 & 0.258 & 4.559 & 11,1065 & $<.001$ & 0.032 & 0.260 \\
\hline RR & 1.18 & $2,9.01$ & .35 & .002 & 0.577 & 2.488 & 11,1066 & .004 & 0.010 & 0.578 \\
\hline HR & 36.88 & $2,9.05$ & $<.001$ & .018 & 0.946 & 25.338 & 11,700 & $<.001$ & 0.020 & 0.947 \\
\hline SC & 4.24 & $2,8.96$ & .051 & .024 & 0.633 & 11.922 & 11,871 & $<.001$ & 0.050 & 0.632 \\
\hline
\end{tabular}


Movements. The LMMs for Movement show significant effects for SC, EMG, and HR response, but not for RR (Figure 3). SC is significantly higher in Dean's $1^{\text {st }}$ movement than in Dean's $2^{\text {nd }}$ and $3^{\text {rd }}$ movements, Brahms' $1^{\text {st }}$ through $3^{\text {rd }}$ movements, and Beethoven's $1^{\text {st }}$ and $2^{\text {nd }}$ movements. SC is also significantly higher in Dean's $4^{\text {th }}$ is than in Brahms' $1^{\text {st }}$ through $3^{\text {rd }}$ movements. SC was lowest in Brahms's $1^{\text {st }}$ movement overall, but increases over the four movements, with SC in the $3^{\text {rd }}$ and the $4^{\text {th }}$ movements being significantly higher than the $1^{\text {st }}$ and $2^{\text {nd }}$ movement. HR increases over the four movements also in Brahms, with HR significantly higher the $4^{\text {th }}$ movement than in the $1^{\text {st }}$ and $2^{\text {nd }}$ movements (but still significantly lower than all Beethoven movements). EMG in Dean's $1^{\text {st }}$ movement is significantly higher than Beethoven's $1^{\text {st }}, 2^{\text {nd }}$ and $4^{\text {th }}$, also Brahms' $1^{\text {st }}$ through $4^{\text {th }}$ movement. EMG in Dean's $4^{\text {th }}$ movement is also significantly higher than Beethoven's $1^{\text {st }}$ and Brahms' $1^{\text {st }}$ and $3^{\text {rd }}$ movements.

Dean's $2^{\text {nd }}$ movement presented via loudspeaker did not lead to striking differences in physiology compared to the live played music.

\section{Relations Between Psychophysiological Measures and Self-Reports}

The random forest regressions revealed higher importance values in SC for feeling energetic, joyful, indifferent, powerful, inspired, agitated and feelings of tenderness $\left(\mathrm{R}^{2}=\right.$ .064; Figure 4), where SC activity increases with feeling energetic, joyful, indifferent and agitated, and decreases with feeling powerful, inspired and feelings of tenderness. Importance values for HR were high for feeling inspired and forgetting about being in a concert (the situation) and surroundings $\left(\mathrm{R}^{2}=.138\right)$, where HR increases with feeling inspired but decreases when participants report they forgot being in a concert and the surroundings. Higher importance values in RR were seen for feelings of tenderness, feeling indifferent, energetic and powerful $\left(\mathrm{R}^{2}=.106\right)$, where $\mathrm{RR}$ increases with feeling energetic and indifferent but decreases with feelings of tenderness and feeling powerful. In EMG, importance values were 
high for feelings of tenderness, feeling relaxed, moved, inspired, and liking (where EMG activity decreases with these feelings; see supplemental material), although the explained variance is low $\left(\mathrm{R}^{2}=.004\right)$.

--- Figure 4 about here ---

Linear models with the latent variables revealed that SC activity was predicted by mixed and negative emotions (explained variance: $\mathrm{R}^{2}(\mathrm{~m})=.015, \mathrm{R}^{2}(\mathrm{c})=.61$; beta estimates, standard errors and significance levels are depicted in Figure 5), and dissociation $\left(\mathrm{R}^{2}(\mathrm{~m})=\right.$ $\left..012, \mathrm{R}^{2}(\mathrm{c})=.62\right)$, i.e., SC activity decreased with higher mixed emotions, and increased with higher negative emotions and dissociation. HR was predicted by positive emotions $\left(\mathrm{R}^{2}(\mathrm{~m})=\right.$ $\left..001, \mathrm{R}^{2}(\mathrm{c})=.94\right)$, i.e., increased with higher positive emotions. RR was only marginally predicted by mixed emotions $(p=.086)$, i.e., decreased with higher mixed emotions. EMG was significantly predicted by negative emotions $\left(\mathrm{R}^{2}(\mathrm{~m})=.010, \mathrm{R}^{2}(\mathrm{c})=.28\right)$, showing that EMG activity increased with higher negative emotions.

--- Figure 5 about here ---

\section{Discussion}

This study investigated aesthetic experiences with music in a live concert context, measured by self-reports of music-induced emotions (GEMIAC, Coutinho \& Scherer, 2017) and absorption (Vroegh, 2018), in combination with physiological measures (skin conductance, zygomaticus major muscle activity, heart rate, and respiration rate). We saw how these measures reflect attentive listening in the concert as a dynamic experience (1) on a global level across three works from different musical periods as well as (2) within works on a structural level (between individual movements). We also (3) extend previously found associations of physiological responses with music-evoked emotions as well as positive and negative aesthetic experiences occurring in a real-world concert setting. 


\section{The Concert Experience}

A concert frame is characterized by presenting a number of works in an intended order, where we observed a rise-and-fall trajectory of emotions (Balteș \& Miu, 2014): Positive and mixed emotions started high for the performance of the classical work, dipped during the contemporary work, and rose again for the romantic work. The negative emotions (tense, agitated) were significantly higher in the contemporary work compared to the classical and romantic works. This shows, on the one hand, that the less familiar work by Dean seemed to be a suitable counterpart to the other two more familiar works, evoking emotions of different valence and arousal (also seen in higher SC and EMG activity) and therefore, extending the range of music-evoked emotions in the concert. On the other hand, the work by Dean did not significantly differ in engagement from the other two works, and the concert lead to an overall positive experience (high overall liking, averaging at 4.10 out of 5). This finding is relatively important, as it supports the idea of general programming in classical concerts to include new works and placing it between well-known canonic works to increase its chance of being 'audience-friendly' (Blackburn, 2016; Gotham, 2014).

In terms of physiology, HR decreased constantly over the course of the concert, from (on average) 72 BPM in Beethoven's $1^{\text {st }}$ movement to 68 BPM in Brahms' $2^{\text {nd }}$ movement. The HR decrease may indicate the general relaxation of the body in the evening (because of a physiological increase in parasympathetic activity) complemented by a calming and relaxing concert experience. Only in the last two movements of the romantic work, HR significantly increased again, but it did not rise to the level of the beginning (i.e., is still significantly lower than Beethoven's $4^{\text {th }}$ movement), potentially reflecting the exciting climactic ending of the Brahms and the awareness of the imminent end of the concert. However, there was the limitation that the order of the works was the same across the concerts. This ecological choice meant that it was not possible to see if this physiological trajectory was evoked by the music (which is relatively unlikely, given that the works exhibited an alternation of movements with 
different arousal potentials, not a generally decreasing trajectory), the concert frame, or by other unspecific factors.

In a similar way to how the self-report measures were most contrasting in the contemporary work, the physiology in the work by Dean also stood out from the other works: $\mathrm{SC}$ in Dean's $1^{\text {st }}$ movement was significantly higher than for the first two movements of both the classical and the romantic works, suggesting that increased skin conductance as evoked by unexpected harmony on a phrase scale (Steinbeis et al., 2006) or single melodic line (Egermann et al., 2013) can be generalized to long-term dissonance across a whole piece. Additionally, the $1^{\text {st }}$ and $4^{\text {th }}$ movements by Dean led to overall significantly higher EMG responses of the zygomaticus muscles (compared to all but Beethoven' $3^{\text {rd }}$ movement). Although inconsistent with positive valence judgments increasing zygomaticus muscle activity (e.g., Kirsch et al., 2016), our results are supported by the finding that dissonant (compared to consonant) music elicits significantly more zygomaticus major activity, potentially reflecting "grimacing” or ironic laughter (Dellacherie et al., 2011). The assumption that zygomaticus major activity is not merely involved with smiling (i.e., reflect pleasure, liking, or other positively valenced reactions and evaluations) is further supported by Wingenbach et al. (2020), who recently showed that the zygomaticus major muscle in facial mimicry was also associated with negatively valenced emotions such as fear and digust, the latter already indicated in a music related setting (Vrana, 1993).

Finally, as it has been theorized that aesthetic experiences in music may be more intensely evoked by a combination of auditory and visual information (Cohen, 2008; Huron, 2008), enhanced in a live performance by adding a sense of creativity and uniqueness to the experience (Auslander, 1999; Brown \& Knox, 2016; Holt, 2010; Minor et al., 2004; Packer \& Ballantyne, 2010), we expected that the recorded music would evoke less intense positive aesthetic experiences compared to the live music. The current study found that the music presented as a recording - rather than live - was rated the lowest for engagement compared to 
four other movements, showing that participants were less concentrated and absorbed and liked it less, probably due to the absence of a main factor of liveness, i.e., the possibility to watch the musicians creating the music in the moment (Seibert et al., 2020). Despite being also in line with other studies comparing a live performance with an audio-visual recording (Coutinho and Scherer, 2017b), the comparison of live and recorded music did not reveal striking significant differences in other self-reports or physiological responses. This result gives rise to the assumption that the situation moderated the aesthetic experience which points to the frame (Goffman, 1974) being a key component in modeling the aesthetic experience (Leder et al., 2004; Locher et al., 2016; Pelowski et al., 2016). This is further supported by the fact that Coutinho and Scherer (2007) compared responses from a live performance in a typical concert venue (church) and the recorded performance in a university lecture hall, i.e., that the difference in emotion may have been due to the lecture hall vs. concert frame, rather than necessarily due to the recorded or liveness per se. However, the limitation here is that only one movement was presented as a recording, and only from the contemporary work. This compromise was made to keep a more "naturalistic" approach as only the contemporary style could entail electro-acoustic elements. Nonetheless, this could be manipulated in future studies to confirm the role of engagement in a live concert setting.

\section{Effects of Compositional Trajectory}

While the performances of the classical and the romantic works hardly differed as whole works in self-reports and physiological responses, similarities as well as differences between movements were evident in these two genres. This could reflect the individual compositional style and strategy of the composers, and thus the overall organization of the work.

Based on the self-report data, participants seemed to perceive three sections of these forms of a sonata: an opening section (Beethoven's and Brahms' $1^{\text {st }}$ movements), an inner section (Beethoven's and Brahms' $2^{\text {nd }}$ movements, and Brahms $3^{\text {rd }}$ movements), and a closing 
section (Beethoven's $3^{\text {rd }}$ movement, Beethoven's and Brahms' $4^{\text {th }}$ movement). The inner sections evoked higher mixed emotions (lower arousal emotions such as being moved, nostalgic, melancholic) and lower positive emotions, while the closing sections evoked lower mixed and higher positive emotions (such as energetic, joyful, inspired) as well as higher engagement. This reflection of the formal structure of the works is depicted in Figure 6.

\section{--- Figure 6 about here ---}

In a similar way that storytelling is perceived in a linear trajectory (Simony et al., 2016), Webster describes a musical "plot” (Webster, 1991, p. 182) and analytically differentiates between the complementary perspectives of cyclic integration (thematicism, tonal organization, p. 194) and the so called through-composition. The idea of the throughcomposition focuses on aspects of gestural phenomena and rhetoric (p. 123), which imply an audience that is capable through anticipation, expectation, and involvement to conceive the work as a whole. Czerny (1848, pp. 33-81) has already suggested that the composition of a sonata cycle incorporates the concept of unity within and throughout its movements, by means of compatibility of affect (tempo, character) and unity of keys (see also Ratner, 1980, p. 322). Within a sonata form, the question arises, how listeners perceive the overall trajectory of the four movements. Hepokoski \& Darcy (2006), for example, proposed a binary-based $(2+2)$ structure, which is mainly based on the symmetrical tonal development from the tonic to a non-tonic key (movements one and two) and its resolving return to the tonic (movements three and four), indicating a higher contrast between the second and the third movement.

The current results can relate to this musical theoretical discourse, albeit more related to the emotional content of the movements (e.g., Balteș \& Miu, 2014): in the classical and romantic works used in this study, there are sections of contrasting emotion/arousal, forming a third section emphasizing the non-tonic space (associated with more tension) of the inner movements between the outer movements in the tonic key. This is in line with Tovey (1956), who has described the 'emotional content' of a sonata cycle and observed that the individual 
movements raised emotional issues which cannot be resolved without the other movements (p. 230). These results show that the reported felt emotions reflect the character/function of the movements, related to previous work showing matched relationships between felt and perceived emotions (Evans \& Schubert, 2008).

Evidence for the different groupings between the classical and romantic works can also be seen in physiology, specifically in the $3^{\text {rd }}$ movements of both works. While the four movements of the classical work do not show much physiological variation, the last two movements from the romantic work show a significant increase in HR and SC, probably reflecting the structure of the romantic work, in which the normative key-order scheme is changed: the third movement is not yet in the tonic key, thus serves as a preparation of the climax and helps establishing a clear area of return and relaxation (tonic key) only with the very last movement (Hepokoski \& Darcy, 2006, p. 340). This interplay of tension (non-tonic) and relaxation (tonic) is a typical stylistic feature of tonal music of the common practice period and affects general expectation and prediction in listeners on all levels (Sears, 2018; Huron, 2006).

These responses within the sonata form specifically occur in the exemplars of the common practice period, but were not present in the contemporary work by Dean. As expected, the linear trajectory of the "suite" led to a very different sequence of emotion and tension ratings. Here, an increase in positive and a decrease in negative emotions from the $1^{\text {st }}$ to the $4^{\text {th }}$ movement of the contemporary work was observed, suggesting that liking may increase with familiarity in musical style (Szpunar at al., 2004) even in complex music (Madison \& Schiölde, 2017). Again, the ratings fit to the overall trajectory of the composition, which cannot be elaborated further in this context. Nonetheless, it has to be noted that contemporary music also plays with expectation, tension and relaxation, but in a more diverse way, and it is very well possible for future studies to draw on schemata that are less common compared to the sonata form, and also in the contemporary style. Taken 
together, the (music-)theoretical approaches fit with the findings of this study, and suggest that there might be at least an implicit perception of inner coherence between movements within the sonata form.

\section{Relations Between Self-Reports and Physiology in an Aesthetic Context}

By operationalizing a musical aesthetic experience with emotions and absorption (Brattico et al., 2013; Brattico \& Pearce, 2013), this study investigated the aesthetic experience of not only positive (e.g., Salimpoor et al, 2019), but negative and mixed valence emotions in response to contemporary, classical, and romantic music performances in combination with continuously acquired psychophysiological measures. Therefore, our analysis was somewhat exploratory, and we conducted two separate analyses with two kinds of predictors for the physiological responses: the single items from each scale and the latent variables obtained from the factor analysis (independent of a specific musical work).

The models from the random forest regressions with single self-report items from the GEMIAC and absorption scales show small to medium effects, while linear mixed effects models with the estimated five latent variables predicting physiology did not reveal noteworthy effects (all $\mathrm{R}^{2}<.02$ ). This means that the results from the random forest regression (i.e., single items) were more successful in explaining the variance in the physiology measures. These results could be due to the fact that latent factors were grouped by valence (where positive and negative emotion factors were both high arousal), whereas physiology tends to also respond to differences in arousal (Baumgartner et al., 2006; Bradley \& Lang, 2000; Egermann et al., 2013; Gomez \& Danuser, 2004). Indeed, our current results support these studies, by showing the strongest relations we found showed typical arousal reactions, e.g., SC and RR increased with high arousal emotions of feeling energetic and agitated, while SC also increased with joyfulness. SC, RR, and EMG responses decreased with lower arousal emotions such as feelings of tenderness. 
Another reason why the single items predicted the physiology better than the latent variables could be because the music in the current study was not chosen to represent one "basic" emotion (Baumgartner et al., 2006; Etzel et al., 2006; Khalfa et al., 2002, 2008; Krumhansl, 1997; Lundqvist et al., 2009) or separate locations on the arousal and valence dimensions (Dillman Carpentier \& Potter, 2015; Egermann et al., 2015; Gomez et al, 2004); rather they were chosen for their potential to evoke diverse and dynamic aesthetic experiences due to their quality as being widely appreciated compositions (for at least two of the works). Therefore, music-induced emotions that cannot be expressed by the music - such as feeling inspired, moved, or even bored - were investigated.

The results reveal that feeling inspired - considered a positive emotion - was associated with a decrease in EMG and SC, but an increase in HR, supporting previous research that heart rate is positively related to the experienced valence of the music (Sammler et al., 2007). Feeling powerful was associated with decreased SC and RR, suggesting that it may be related to a calm state of mind. Interestingly, we found that feeling indifferent/bored was associated with increased SC and RR. We also found that being moved and liking ratings were associated with a decrease of smiling muscle activity, which somewhat contradicts what we were expecting (Bradeley \& Lang, 2000; Kirsch et al., 2016). An explanation for the current findings might be that idea that more positive musical judgments are associated with motor inhibition indices, such as smaller eye blink amplitudes (Roy et al., 2009), slower response times, and a higher amplitude of a motor inhibition N2/P3 component in an electroencephalography (EEG) event-related potential brain response (Sarasso, 2019). According to this perspective, positive aesthetic emotions and judgements inhibit muscle activity, maximising attentional resources on the perception of the aesthetic object. However, as mentioned above, the negative relationship with EMG activity of the smiling muscle and positive feelings/liking, also could be due to the activation of EMG muscles reflecting a negative experience, such as a grimace (e.g., Dellacherie et al., 2011; Wingenbach et al., 
2020). As we only took measurements from one facial EMG muscle, our current findings are not conclusive as to whether a negative experience is result of an inhibition of this muscle during more positive emotions or an activation in response to negative felt emotions but it could be possible that both mechanisms were at play here.

The physiology seemed to reflect two absorption items as well: HR decreased with the items forgetting about being in a concert and the surroundings, which is in line with the above made conclusion that the overall concert experience is reflected in $\mathrm{HR}$ - mirrored in items of dissociation, i.e., the exclusion of other content from the phenomenal field (Butler, 2004; Vroegh, 2018).

Although we show how physiology may be linked to emotions (on general arousalvalence dimensions) and absorption, a limitation of these measures is that they do not directly index emotions without being associated with self-reports on emotions and feelings. Hence, this study is an attempt at formulating more general conclusions on which emotions and physiological responses occur during a classical concert in response to different kinds of music. Further research may need to reduce this set of emotions and include continuous ratings to track the relations between continuous changes in rating behavior and physiology.

\section{Conclusion}

This exploratory study considered the aesthetic experience - as operationalized by music-induced emotions and absorption - in combination with physiology across whole multi-movement works of music of varying styles framed in a typical classical concert setting. Conducting research in a frame where the music is placed for optimum attention (e.g., dimmed lights, expected total silence) we observed firstly, (a) a rise-and-fall trajectory of emotions - with the contemporary work leading to higher negatively valenced emotions embedded in an overall highly liked and appreciated concert and (b) that the movement presented as a recording had lower engagement than movements performed live. These results 
tentatively highlight the programming and "liveness" as components of the concert frame which may influence the aesthetic experience - though it remains to be more systematically manipulated in future studies to confirm this effect. Secondly, investigating the experience of whole works yielded novel insights into the perception of a (cyclic) multi-movement work. Emotional and - in part - physiological responses mirrored the functions across movements in familiar classical and romantic works representing variations of the sonata form, contrasting the unfamiliar contemporary work (in the form of a suite), which did not follow such a trajectory. Thirdly, by selecting naturalistic music for their potential to evoke diverse aesthetic experiences, we extend previous results by showing that physiological responses reflect a range of music-evoked emotions relating to both positive and negative aesthetic experiences. To elaborate on these findings, it seems exploratory research is required in combination with more controlled studies to further understand the interplay between compositional conventions and musical expectations, between the score and the act of performance in a specific frame, and the resulting live concert experience (Toelle \& Sloboda, 2019; Wald-Fuhrmann et al., submitted). 


\section{References}

Ardizzi, M., Calbi, M., Tavaglione, S., Umiltà, M. A., \& Gallese, V. (2020). Audience spontaneous entrainment during the collective enjoyment of live performances: physiological and behavioral measurements. Scientific Reports, 10(1), 1-12. https://doi.org/10.1038/s41598-020-60832-7

Balteș, F. R., \& Miu, A. C. (2014). Emotions during live music performance: Links with individual differences in empathy, visual imagery, and mood. Psychomusicology: Music, Mind, and Brain, 24(1), 58-65. https://doi.org/10.1037/pmu0000030

Bannister, S. (2020). A survey into the experience of musically induced chills: Emotions, situations and music. Psychology of Music, 48(2), 297-314. https://doi.org/10.1177/0305735618798024

Bartoń, K. (2015). MuMIn: multi-model inference. R package version 1. 43. 17. http://r-forge r-project.org/projects/mumin/.

Bates D, Mächler M, Bolker B, Walker S (2015). "Fitting Linear Mixed-Effects Models Using 1me4.” Journal of Statistical Software, 67(1), 1-48. doi: 10.18637/jss.v067.i01.

Baumgartner, T., Esslen, M., \& Jäncke, L. (2006). From emotion perception to emotion experience: Emotions evoked by pictures and classical music. International Journal of Psychophysiology, 60(1), 34-43. https://doi.org/10.1016/j.ijpsycho.2005.04.007

Benedek, M., \& Kaernbach, C. (2010). A continuous measure of phasic electrodermal activity. Journal of Neuroscience Methods, 190(1), 80-91. https://doi.org/10.1016/j.jneumeth.2010.04.028

Berlyne, D. E. (1960). Conflict, arousal, and curiosity. New York, NY, US: McGraw-Hill Book Company. xii 350. https://doi.org/10.1037/11164-000

Beveridge, S., \& Knox, D. (2009). An exploration of the effect of structural and acoustical features on perceived musical emotion. Proceedings of Audio Mostly 2009 - A Conference on Interaction with Sound, 93-98.

Blackburn, A. (2016). The role repertoire choice has in shaping the identity and functionality of a chamber music ensemble. ICMPC14, (July 2016), 583-587.

Blood, A. J., \& Zatorre, R. J. (2001). Intensely pleasurable responses to music correlate with activity in brain regions implicated in reward and emotion. Proceedings of the national academy of sciences, 98(20), 11818-11823. https://doi.org/10.1073/pnas.191355898

Bradley, M., \& Lang, P. (2000). Affective reactions to acoustic stimuli. Psychophysiology, 37. https://doi.org/10.1111/1469-8986.3720204

Brattico, E., Bogert, B., \& Jacobsen, T. (2013). Toward a neural chronometry for the aesthetic experience of music. Frontiers in Psychology, 4:206, 1-21. https://doi.org/10.3389/fpsyg.2013.00206

Brattico, E., \& Pearce, M. (2013). The neuroaesthetics of music. Psychology of Aesthetics, Creativity, and the Arts, 7(1), 48-61. https://doi.org/10.1037/a0031624 
Bullack, A., Büdenbender, N., Roden, I., \& Kreutz, G. (2018). Psychophysiological responses to "'happy" and "sad" music: A replication study. Music Perception, 35(4), 502517. https://doi.org/https://doi.org/10.1525/MP.2018.35.4.502

Burland, K., \& Pitts, S. (Eds.). (2016). SEMPRE studies in the psychology of music. Coughing and clapping: Investigating audience experience (First issued in paperback 2016). Routledge, Taylor \& Francis Group.

Butler, L. D. (2004). The dissociations of everyday life. Journal of Trauma and Dissociation, $5,1-11$.

Cacioppo, J. T., Berntson, G., Larsen, J., Poehlmann, K., \& Ito, T. (2000). The Psychophysiology of Emotions. In Handbook of emotions (pp. 173-191). https://doi.org/10.1016/B978-0-08-100508-8.00004-7

Calvo-Merino, B., Jola, C., Glaser, D. E., \& Haggard, P. (2008). Towards a sensorimotor aesthetics of performing art. Consciousness and Cognition, 17. https://doi.org/10.1016/j.concog.2007.11.003

Cannam, C., Landone, C., \& Sandler, M. (2010). Sonic visualiser: an open source application for viewing, analysing, and annotating music audio files. MM'10, 1467. https://doi.org/10.1145/1873951.1874248

Chaffin, R., Lemieux, A., \& Chen, C. (2007). "It is Different Each Time I Play": Variability in highly prepared musical performance. Music Perception. 24(5), 455-472. https://doi.org/10.1525/mp.2007.24.5.455

Christensen, J. F., \& Calvo-Merino, B. (2013). Dance as a subject for empirical aesthetics. Psychology of Aesthetics, Creativity, and the Arts, 7(1), 76-88. https://doi.org/10.1037/a0031827

Cohen, A. J. (2008). Music in performance arts: Film, theatre and dance. The Oxford Handbook of Music Psychology, (November 2019), 1-16. https://doi.org/10.1093/oxfordhb/9780199298457.013.0041

Cohen, J. (1988). Statistical power analysis for the behavioural sciences.

Cook, N. (1987). The Perception of Large-Scale Tonal Closure. Music Perception, 5(2), $197-$ 205. https://doi.org/10.2307/40285392

Cook, N. (2013). Beyond the Score: Music as Performance. New York: Oxford University Press.

Coutinho, E., \& Scherer, K. R. (2017a). Introducing the GEneva Music-induced Affect Checklist (GEMIAC): A brief instrument for the rapid assessment of musically induced emotions. Music Perception, 34(4), 1225-1228. https://doi.org/https://doi.org/10.1525/mp.2017.34.4.371

Coutinho, E., \& Scherer, K. R. (2017b). The effect of context and audio-visual modality on emotions elicited by a musical performance. Psychology of Music, 45(4), 550-569. https://doi.org/10.1177/0305735616670496

Craig, D. G. (2005). An exploratory study of physiological changes during 'chills' induced by music. Musicae Scientiae, 9(2), 273-287. https://doi.org/https://doi.org/10.1177/102986490500900207 
Cross, E. S. (2015). Beautiful embodiment: The shaping of aesthetic preference by personal experience. In Art, Aesthetics, and the Brain. Oxford University Press, Oxford (pp. 189-208). https://doi.org/10.1093/acprof:oso/9780199670000.003.0010

Czerny, C. (1848). School of Practical Composition, Op. 600. (J. Bishop. Trans.). London: Robert Cocks \& Co. (Original work published 1930)

de Jong, M. A., van Mourik, K. R., \& Schellekens, H. M. C. (1973). A physiological approach to aesthetic preference. Psychotherapy and psychosomatics, 22(1), 46-51.

Dellacherie, D., Roy, M., Huguewille, L., Peretz, I., \& Samson, S. (2011). The effect of musical experience on emotional self-reports and psychophysiological responses to dissonance. Psychophysiology, 48(3), 337-349.

Dillman Carpentier, F. R., \& Potter, R. F. (2007). Effects of music on physiological arousal: Explorations into tempo and genre. Media Psychology, 10(3), 339-363. https://doi.org/10.1080/15213260701533045

Doric String Quartet (2015). Epitaphs. On Brett Dean [CD]. Chandos.

Eerola, T., Vuoskoski, J. K., \& Kautiainen, H. (2016). Being moved by unfamiliar sad music is associated with high empathy. Frontiers in Psychology, 7, 1-12. https://doi.org/10.3389/fpsyg.2016.01176

Eerola, T., Vuoskoski, J. K., Peltola, H. R., Putkinen, V., \& Schäfer, K. (2018). An integrative review of the enjoyment of sadness associated with music. Physics of Life Reviews, 25, 100-121. https://doi.org/10.1016/j.plrev.2017.11.016

Egermann, H., Fernando, N., Chuen, L., \& McAdams, S. (2015). Music induces universal emotion-related psychophysiological responses: Comparing Canadian listeners to Congolese Pygmies. Frontiers in Psychology, 6, 1-9. https://doi.org/10.3389/fpsyg.2015.00341

Egermann, H., Pearce, M. T., Wiggins, G. A., \& McAdams, S. (2013). Probabilistic models of expectation violation predict psychophysiological emotional responses to live concert music. Cognitive, Affective and Behavioral Neuroscience, 13(3), 533-553. https://doi.org/10.3758/s13415-013-0161-y

Egermann, H., Sutherland, M. E., Grewe, O., Nagel, F., Kopiez, R., \& Altenmüller, E. (2011). Does music listening in a social context alter experience. Musicae Scientiae, 15(3), 307-323.

Etzel, J. A., Johnsen, E. L., Dickerson, J., Tranel, D., \& Adolphs, R. (2006). Cardiovascular and respiratory responses during musical mood induction. International Journal of Psychophysiology, 61(1), 57-69. https://doi.org/10.1016/j.ijpsycho.2005.10.025

Evans, P., \& Schubert, E. (2008). Relationships between expressed and felt emotions in music. Musicae Scientiae, 12(1), 75-99. https://doi.org/10.1177/102986490801200105

Fechner, G.T. (1876). Vorschule der Aesthetik (Experimental Aesthetics; "Pre-School" of Aesthetics). Leipzig, Germany: Breitkopf \& Härtel. 
Frith, C. D., \& Allen, H. A. (1983). The skin conductance orienting response as an index of attention. Biological Psychology, 17, 27-39. https://doi.org/10.1017/CBO9781107415324.004

Gabrielsson, A. (2011). Strong experiences with music: Music is much more than just music. Oxford University Press.

Gabrielsson, A., \& Lindström Wik, S. (2003). Strong Experiences Related to Music: A descriptive System. Musicae Scientiae, 7(2), 157-217. https://doi.org/10.1177/102986490300700201

Gilmore, S. (1993). Tradition and novelty in concert programming: Bringing the artist back into cultural analysis. Sociological Forum, 8(2), 221-242. https://doi.org/10.1007/BF01115491

Goehr, L. (1992). The Imaginary Museum of Musical Works: An Essay in the Philosophy of Music. Oxford: Clarendon Press

Goffman, Erving. 1974. Frame analysis: an essay on the organization of experience. Cambridge, Mass: Harvard University Press.

Goldstein, A. (1980). Thrills in response to music and other stimuli. Physiological Psychology, 8(1), 126-129. https://doi.org/10.3758/BF03326460

Gomez, P., \& Danuser, B. (2004). Affective and physiological responses to environmental noises and music. International Journal of Psychophysiology, 53(2), 91-103. https://doi.org/10.1016/j.ijpsycho.2004.02.002

Goodchild, M., Wild, J., \& McAdams, S. (2017). Exploring emotional responses to orchestral gestures. Musicae Scientiae, 23(1), 25-49. https://doi.org/10.1177/1029864917704033

Gotham, M. (2014). Coherence in concert programming: A view from the U.K. . International Review of the Aesthetics and Sociology of Music, 45(2), 293-309.

Gotlieb, H., \& Konečni, V. J. (1985). The effects of instrumentation, playing style, and structure in the Goldberg Variations by Johann Sebastian Bach". Music Perception, 5(2), 87-102. https://doi.org/10.2307/40285393

Greenaway, K. H., Kalokerinos, E. K., \& Williams, L. A. (2018). Context is Everything (in Emotion Research). Social and Personality Psychology Compass, 12(6), 1-18. https://doi.org/10.1111/spc3.12393

Grewe, O., Nagel, F., Kopiez, R., \& Altenmüller, E. (2007). Emotions Over Time: Synchronicity and Development of Subjective, Physiological, and Facial Affective Reactions to Music. Emotion, 7(4), 774-788. https://doi.org/10.1037/15283542.7.4.774

Grey, J. M., \& Gordon, J. W. (1978). Perceptual effects of spectral modifications on musical timbres. The Journal of the Acoustical Society of America, 63(5), 1493. https://doi.org/10.1121/1.381843

Guhn, M., Hamm, A., \& Zentner, M. (2007). Physiological and musico-acoustic correlates of the chill response. Music Perception, 24(5), 473-484. https://doi.org/https://doi.org/10.1525/MP.2007.24.5.473 
Hargreaves, D. J., MacDonald, R. A. R., \& Miell, D. E. (2005). How do people communicate using music? In D. E. Miell, R. A. R. MacDonald, \& D. J. Hargreaves (Eds.), Musical communication (pp. 1-25). Oxford, UK: Oxford University Press.

Hargreaves, D. J., \& North, A. C. (2013). Experimental aesthetics and liking for music. In Handbook of Music and Emotion: Theory, Research, Applications (Vol. 15, pp. 583605). https://doi.org/10.1093/acprof

Herbert, R. (2011). Everyday Music Listening: Absorption, Dissociation and Trancing. Aldershot: Ashgate.

Heister, H. W. (1983). Das Konzert: Theorie einer Kulturform (Vol. 1 and 2). Wilhelmshaven, Germany: Noetzel.

Hepokoski, J., Darcy, W. (2006). Elements of Sonata Theory: Norms, Types, and Deformations in the Late-Eighteenth-Century Sonata. New York: Oxford University Press

Hodges, D. A. (2011) Psychophysiological measures. In: Juslin PN, Sloboda J, editors. Handbook of music and emotion: Theory, research, applications. Oxford University Press, p. 279-311.

Hoffding, S. (2018). A phenomenology of musical absorption. Cham: Palgrave Macmillan.

Hewett, I. (2017). Europe. In M. Church (Ed.), The Other Classical Musics: Fifteen Great Traditions. Yearbook for Traditional Music (Vol. 49, pp. 216-245): Boydell and Brewer

Hunter, P. G., Schellenberg, E. G., \& Schimmack, U. (2008). Mixed affective responses to music with conflicting cues. Cognition and Emotion, 22(2), 327-352. https://doi.org/10.1080/02699930701438145

Caplin, W. E. (1998). Classical Form: A Theory of Formal Functions for the Instrumental Music of Haydn, Mozart, and Beethoven. New York: Oxford University Press

Huron, D. (2006). Sweet anticipation: Music and the psychology of expectation. The MIT Press.

Huron, D. (2008). Aesthetics. The Oxford Handbook of Music Psychology, (November), 114. https://doi.org/10.1093/oxfordhb/9780199298457.013.0014

Isik, A. I., \& Vessel, E. A. (2019). Continuous ratings of movie watching reveal idiosyncratic dynamics of aesthetic enjoyment. PLoS ONE, 14(10), 1-21. https://doi.org/10.1371/journal.pone.0223896

Iverson, P., \& Krumhansl, C. L. (1993). Isolating the dynamic attributes of musical timbre. Journal of the Acoustical Society of America, 94(5), 2595-2603. https://doi.org/10.1121/1.407371

Juslin, P. N. (2013). From everyday emotions to aesthetic emotions: Towards a unified theory of musical emotions. Physics of Life Reviews, 10(3), 235-266. https://doi.org/10.1016/j.plrev.2013.05.008

Juslin, P. N., Liljeström, S., Västfjäll, D., Barradas, G., \& Silva, A. (2008). An Experience Sampling Study of Emotional Reactions to Music: Listener, Music, and Situation. Emotion, 8(5), 668-683. https://doi.org/10.1037/a0013505 
Juslin, P. N., \& Västfjäll, D. (2008). Emotional responses to music: The need to consider underlying mechanisms. Behavioral and Brain Sciences, 31(5), 595-596. https://doi.org/10.1017/S0140525X08005293

Karno, M., \& Konecni, V. (1992). The Effects of Structural Interventions in the First Movement of Mozart's Symphony in G Minor K . 550 on Aesthetic Preference. Music Perception, 10(1), 63-72.

Khalfa, S., Peretz, I., Jean-Pierre, B., \& Manon, R. (2002). Event-related skin conductance responses to musical emotions in humans. Neuroscience Letters, 328(2), 145-149. https://doi.org/10.1016/S0304-3940(02)00462-7

Khalfa, S., Roy, M., Rainville, P., Dalla Bella, S., \& Peretz, I. (2008). Role of tempo entrainment in psychophysiological differentiation of happy and sad music? International Journal of Psychophysiology, 68(1), 17-26. https://doi.org/10.1016/j.ijpsycho.2007.12.001

Kirsch, L. P., Snagg, A., Heerey, E., \& Cross, E. S. (2016). The impact of experience on affective responses during action observation. PloS ONE, 11(5), e0154681. https://doi.org/10.1371/journal.pone.0154681

Klorman, E. (2016). Mozart's Music of Friends: Social Interplay in the Chamber Works. Cambridge: Cambridge University Press

Koelsch, S., Gunter, T., Friederici, A., \& Schroger, E. (2000). Brain indices of music processing: "nonmusicians" are musical. Journal of Cognitive Neuroscience, 12(3), 520-541. https://doi.org/10.1162/089892900562183

Kolb, B. M. (2000). You call this fun? Reactions of young first-time attendees to a classical concert. Music Industry Issues and Studies, 1(1), 13-28.

Kostoulas, T., Chanel, G., Muszynski, M., Lombardo, P., \& Pun, T. (2015). Identifying aesthetic highlights in movies from clustering of physiological and behavioral signals. 2015 7th International Workshop on Quality of Multimedia Experience, QoMEX 2015. https://doi.org/10.1109/QoMEX.2015.7148098

Kreibig SD. (2010) Autonomic nervous system activity in emotion: A review. Biolological Psychology. 84(3):394-421.

Krumhansl, C. L. (1997). An exploratory study of musical emotions and psychophysiology. Canadian Journal of Experimental Psychology/Revue Canadienne de Psychologie Expérimentale, 51(4), 336-353. https://doi.org/10.1037/1196-1961.51.4.336

Kuehnast, M., Wagner, V., Wassiliwizky, E., Jacobsen, T., \& Menninghaus, W. (2014). Being moved: Linguistic representation and conceptual structure. Frontiers in Psychology, 5. https://doi.org/10.3389/fpsyg.2014.01242

Kuznetsova, A., Brockhoff, P. B., Christensen, R. H. B. (2017). lmerTest Package: Tests in Linear Mixed Effects Models. Journal of Statistical Software, 82(13), 1-26. doi: 10.18637/jss.v082.i13.

Lamont, A. M. (2011). University students' strong experiences of music: Pleasure, engagement, and meaning. Musicae Scientiae, 15(2), 229-249. https://doi.org/10.1177/1029864911403368

Lange, E. B., \& Frieler, K. (2018). Challenges and opportunities of predicting musical emotions with perceptual and automatized features. Music Perception: An Interdisciplinary Journal, 36(2), 217-242. 
Lange, E. B., Zweck, F., \& Sinn, P. (2017). Microsaccade-rate indicates absorption by music listening. Consciousness and Cognition, 55, 59-78. https://doi.org/10.1016/j.concog.2017.07.009

Lartillot, O., \& Toiviainen, P. (2007). MIR in Matlab (II): a toolbox for musical feature extraction from audio. Proceedings of the 8th International Conference on Music Information Retrieval, 237-244.

Leder, H., Belke, B., Oeberst, A., \& Augustin, D. (2004). A model of aesthetic appreciation and aesthetic judgments. British Journal of Psychology, 95(4), 489-508. https://doi.org/10.1348/0007126042369811

Leder, H., \& Nadal, M. (2014). Ten years of a model of aesthetic appreciation and aesthetic judgments: The aesthetic episode - Developments and challenges in empirical aesthetics. British Journal of Psychology, 105(4), 443-446. https://doi.org/10.1111/bjop.12084

Lenth, R., Singmann, H., Love, J., Buerkner, P., \& Herve, M. (2018). Emmeans: Estimated marginal means, aka least-squares means. $R$ package version, 1.4.8

Levinson, J. (2003). The Oxford handbook of aesthetics. Oxford: Oxford University Press.

Liaw, A. and Wiener, M. (2002). Classification and Regression by randomForest. R News 2(3), 18-22.

Liljeström, S., Juslin, P., \& Västfjäll, D. (2012). Experimental evidence of the roles of music choice, social context, and listener personality in emotional reactions to music. Psychology of Music, 41(5), 570-599.

Locher, P., Overbeeke, K., \& Wensveen, S. (2016). Aesthetic Interaction: A Framework. Design Issues. 26(2), 70-79.

Lokki, T., Pätynen, J., Kuusinen, A., \& Tervo, S. (2012). Disentangling preference ratings of concert hall acoustics using subjective sensory profiles. The Journal of the Acoustical Society of America, 132(5), 3148-3161. https://doi.org/10.1121/1.4756826

Lokki, T., Pätynen, J., Kuusinen, A., Vertanen, H., \& Tervo, S. (2011). Concert hall acoustics assessment with individually elicited attributes. The Journal of the Acoustical Society of America, 130(2), 835-849. https://doi.org/10.1121/1.3607422

Lundqvist, L.-O., Carlsson, F., Hilmersson, P., \& Juslin, P. (2009). Emotional responses to music: experience, expression, and physiology. Psychology of Music, 37(1), 61-90.

Madison, G., \& Schiölde, G. (2017). Repeated listening increases the liking for music regardless of its complexity: Implications for the appreciation and aesthetics of music. Frontiers in Neuroscience, 11, 1-13. https://doi.org/10.3389/fnins.2017.00147

McAdams, S., Winsberg, S., Donnadieu, S., De Soete, G., \& Krimphoff, J. (1995). Perceptual scaling of synthesized musical timbres: Common dimensions, specificities, and latent subject classes. Psychological Research, 58(3), 177-192. https://doi.org/10.1007/BF00419633

Menninghaus, W., Wagner, V., Hanich, J., Wassiliwizky, E., Kuehnast, M., \& Jacobsen, T. (2015). Towards a psychological construct of being moved. PLoS ONE, 10(6), 33-35. https://doi.org/10.1371/journal.pone.0128451 
Menninghaus, W., Wagner, V., Wassiliwizky, E., Schindler, I., Hanich, J., Jacobsen, T., \& Koelsch, S. (2019). What are aesthetic emotions? Psychological Review, 126(2), 171 195. https://doi.org/10.1037/rev0000135

Mourot, L., Bouhaddi, M., Perrey, S., Rouillon, J. D., \& Regnard, J. (2004). Quantitative Poincaré plot analysis of heart rate variability: Effect of endurance training. European Journal of Applied Physiology, 91(1), 79-87. https://doi.org/10.1007/s00421-0030917-0

Müllensiefen, D., Gingras, B., Musil, J., \& Stewart, L. (2014). The musicality of nonmusicians: An index for assessing musical sophistication in the general population. PLoS ONE, 9(2). https://doi.org/10.1371/journal.pone.0089642

Omigie, D., Frieler, K., Bär, C., Muralikrishnan, R., Wald-Fuhrmann, M., \& Fischinger, T. (2019). Experiencing Musical Beauty: Emotional Subtypes and Their Physiological and Musico-Acoustic Correlates. Psychology of Aesthetics, Creativity, and the Arts. https://doi.org/10.1037/aca0000271

Oostenveld, R., Fries, P., Maris, E., \& Schoffelen, J. M. (2011). FieldTrip: Open source software for advanced analysis of MEG, EEG, and invasive electrophysiological data. Computational Intelligence and Neuroscience, 2011. https://doi.org/10.1155/2011/156869

Palmer, C. (1997). Music performance. Annual Review of Psychology, 48, 115-138. https://doi.org/10.1146/annurev.psych.48.1.115

Panksepp, J. (1995). The Emotional Sources of "Chills" Induced by Music. Music Perception, 13(2), 171-207. https://doi.org/10.2307/40285693

Panzarella, R. (1980). The phenomenology of aesthetic peak experience. J. Humanistic Psychology, 20(1), 69-85.

Pelowski, M., Akiba, F., \& Palacios, V. (2012). Satori, Koan and aesthetic experience: Exploring the 'realisation of emptiness' in Buddhist enlightenment via an empirical study of modern art. Psyke \& Logos, 2(2), 236-268.

Pelowski, M., Markey, P. S., Forster, M., Gerger, G., \& Leder, H. (2017). Move me, astonish me... delight my eyes and brain: The Vienna Integrated Model of top-down and bottom-up processes in Art Perception (VIMAP) and corresponding affective, evaluative, and neurophysiological correlates. Physics of Life Reviews, 21, 80-125. https://doi.org/10.1016/j.plrev.2017.02.003

Pelowski, M., Markey, P. S., Lauring, J. O., \& Leder, H. (2016). Visualizing the impact of art: An update and comparison of current psychological models of art experience. Frontiers in Human Neuroscience, 10, 1-21. https://doi.org/10.3389/fnhum.2016.00160

R Core Team. (2014). R: A language and environment for statistical computing. Vienna, Austria: R Foundation for Statistical Computing

Ratner, L. (1980). Classic Music: Expression, Form, and Style. New York: Schirmer Books

Revelle, W. (2019). psych: Procedures for Psychological, Psychometric, and Personality Research. Northwestern University, Evanston, Illinois. R package version 1.9.12, https://CRAN.R-project.org/package=psych. 
Rickard, N. S. (2004). Intense emotional responses to music: a test of the physiological arousal hypothesis. Psychology of Music, 32(4), 371-388.

Roy, M., Mailhot, J. P., Gosselin, N., Paquette, S., \& Peretz, I. (2009). Modulation of the startle reflex by pleasant and unpleasant music. International Journal of Psychophysiology, 71(1), 37-42.

Russell, J. A., \& Pratt, G. (1980). A description of the affective quality attributed to environments. Journal of Personality and Social Psychology, 38(2), 311-322. https://doi.org/10.1037/0022-3514.38.2.311

Salimpoor, V. N., Benovoy, M., Longo, G., Cooperstock, J. R., \& Zatorre, R. J. (2009). The rewarding aspects of music listening are related to degree of emotional arousal. PLoS ONE, 4(10). https://doi.org/10.1371/journal.pone.0007487

Sammler, D., Grigutsch, M., Fritz, T., \& Koelsch, S. (2007). Music and emotion: Electrophysiological correlates of the processing of pleasant and unpleasant music. Psychophysiology, 44(2), 293-304. https://doi.org/10.1111/j.1469-8986.2007.00497.x

Sarasso, P., Ronga, I., Pistis, A., Forte, E., Garbarini, F., Ricci, R., \& Neppi-Modona, M. (2019). Aesthetic appreciation of musical intervals enhances behavioural and neurophysiological indexes of attentional engagement and motor inhibition. Scientific Reports, 9(1), 1-14.

Schaal, N. K., Bauer, A.-K. R., \& Müllensiefen, D. (2014). Der Gold-MSI: Replikation und Validierung eines Fragebogeninstrumentes zur Messung Musikalischer Erfahrenheit anhand einer deutschen Stichprobe. Musicae Scientiae, 18(4), 423-447. https://doi.org/10.1177/1029864914541851

Schäfer, T., \& Sedlmeier, P. (2009). From the functions of music to music preference. Psychology of Music, 37(3), 279-300. https://doi.org/10.1177/0305735608097247

Scherer, K. R., Trznadel, S., Fantini, B., \& Coutinho, E. (2018). Assessing Emotional Experiences of Opera Spectators in Situ. Psychology of Aesthetics, Creativity, and the Arts, 13(3), 244-258. https://doi.org/10.1037/aca0000163

Scherer, K. R., \& Zentner, M. R. (2008). Music evoked emotions are different - more often aesthetic than utilitarian. Behavioral and Brain Sciences, 31(5), 559-621. https://doi.org/10.1017/S0140525X08005505

Schindler, I., Hosoya, G., Menninghaus, W., Beermann, U., Wagner, V., Eid, M., \& Scherer, K. R. (2017). Measuring aesthetic emotions: A review of the literature and a new assessment tool. PLoS ONE, 12(6), 8-11. https://doi.org/10.17605/OSF.IO/Q8ZV5

Seibert, C., Toelle, J., \& Wald-Fuhrmann, M. (2020). The Classical Concert as an Object of Empirical Aesthetics. In: Tröndle M, editor. Classical concert studies. A companion to contemporary research and performance. Routledge.

Silvia, P., \& Berg, C. (2011). Finding movies interesting: How appraisals and expertise influence the aesthetic experience of film. Empirical Studies of the Arts, 29(1), 73-88. https://doi.org/10.2190/EM.29.1.e

Simony, E., Honey, C. J., Chen, J., Lositsky, O., Yeshurun, Y., Wiesel, A., \& Hasson, U. (2016). Dynamic reconfiguration of the default mode network during narrative comprehension. Nature communications, 7, 12141. 
Sloboda, J. A. (1985). The Musical Mind. The Cognitive Psychology of Music. London: Oxford University Press.

Sloboda, J. (1991). Music structure and emotional response: some empirical findings. Psychology of Music, 19, 110-120. https://doi.org/10.1177/0305735691192002

Sosnowski, M., Clark, E., Latif, S., Macfarlane, P. W., \& Tendera, M. (2005). Heart rate variability fraction - A new reportable measure of 24-hour R-R interval variation. Annals of Noninvasive Electrocardiology, 10(1), 7-15. https://doi.org/10.1111/j.1542474X.2005.00579.x

Steinbeis, N., Koelsch, S., \& Sloboda, J. A. (2006). The role of harmonic expectancy violations in musical emotions: evidence from subjective, physiological, and neural responses. Journal of Cognitive Neuroscience, 18(8), 1380-1393. https://doi.org/10.1162/jocn.2006.18.8.1380

Sutherland, M. E., Grewe, O., Egermann, H., Nagel, F., Kopiez, R., \& Altenmüller, E. (2009). The influence of social situations on music listening. Annals of the New York Academy of Sciences, 1169, 363-367. https://doi.org/10.1111/j.17496632.2009.04764.x

Szpunar, K. K., Schellenberg, G. E., \& Pliner, P. (2004). Liking and memory for musical stimuli as a function of exposure. Journal of Experimental Psychology: Learning Memory and Cognition, 30(2), 370-381. https://doi.org/10.1037/0278-7393.30.2.370

Taruffi, L., \& Koelsch, S. (2014). The paradox of music-evoked sadness: An online survey. PLoS ONE, 9(10), 1-17. https://doi.org/10.1371/journal.pone.0110490

Taruffi, L., Pehrs, C., Skouras, S., \& Koelsch, S. (2017). Effects of sad and happy music on mind-wandering and the default mode network. Scientific Reports, 7(1), 1-10. https://doi.org/10.1038/s41598-017-14849-0

Thorau, C., \& Ziemer, H. (Eds.). (2019). Oxford Handbooks. The Oxford handbook of music listening in the 19th and 20th centuries. Oxford University Press.

Toelle, J., \& Sloboda, J. A. (2019). The audience as artist? The audience's experience of participatory music. Musicae Scientiae, 1-25. https://doi.org/10.1177/1029864919844804

Tovey, D. F. (1956). The Forms of Music. New York: Meridian

Tramo, M. J., Cariani, P. A., Delgutte, B., \& Braida, L. D. (2001). Neurobiological foundations for the theory of harmony in Western tonal music. Annals of the New York Academy of Sciences, 930, 92-116. https://doi.org/10.1111/j.17496632.2001.tb05727.x

Trost, W., Ethofer, T., Zentner, M., \& Vuilleumier, P. (2012). Mapping aesthetic musical emotions in the brain. Cerebral Cortex, 22(12), 2769-2783.

Tschacher, W., Kirchberg, V., van den Berg, K., Greenwood, S., Wintzerith, S., \& Tröndle, M. (2012). Physiological correlates of aesthetic perception of artworks in a museum. Psychology of Aesthetics, Creativity, and the Arts, 6(1), 96-103. https://doi.org/10.1037/a0023845

Tzanetakis, G., \& Cook, P. (2002). Musical genre classification of audio signals. IEEE Transactions on Speech and Audio Processing, 10(5), 293-302. https://doi.org/10.1109/TSA.2002.800560 
Vrana, S. R. (1993). The psychophysiology of disgust: Differentiating negative emotional contexts with facial EMG. Psychophysiology, 30(3), 279-286. https://doi.org/10.1111/j.1469-8986.1993.tb03354.x

Vroegh, Thijs (2018). The pleasures of getting involved into the music: Absorption, and its role in the aesthetic appreciation of music, Dissertation (Goethe-Universität Frankfurt). http://publikationen.ub.uni-frankfurt.de/frontdoor/index/index/docId/47549

Vuoskoski, J. K., \& Eerola, T. (2017). The Pleasure Evoked by Sad Music Is Mediated by Feelings of Being Moved. Frontiers in Psychology, 8, 439. https://doi.org/10.3389/fpsyg.2017.00439

Vuvan, D. T., \& Hughes, B. (2019). Musical style affects the strength of harmonic expectancy. Music \& Science, 2, 1-9. https://doi.org/10.1177/2059204318816066

Wald-Fuhrmann, M., Egermann, H., O’Neill, K., Czepiel, A., Weining, C., Deborah Meier, D., Tascher, W., Uhde, F., Toelle, J., \& Tröndle, M. (submitted). Music Listening in Classical Concerts: Theory, Literature Review, and Research Program.

Wassiliwizky, E., Koelsch, S., Wagner, V., Jacobsen, T., \& Menninghaus, W. (2017). The emotional power of poetry: Neural circuitry, psychophysiology and compositional principles. Social Cognitive and Affective Neuroscience, 12(8), 1229-1240. https://doi.org/10.1093/scan/nsx069

Wassiliwizky, E., Wagner, V., Jacobsen, T., \& Menninghaus, W. (2015). Art-elicited chills indicate states of being moved. Psychology of Aesthetics, Creativity, and the Arts, 9(4), 405-416. https://doi.org/10.1037/aca0000023

Weber, W. (2003). Consequences of the canon: the institutionalization of enmity between contemporary and classical music. Common Knowledge, 9(1), 78-99. https://doi.org/10.1215/0961754x-9-1-78

Webster, J. (1991). Haydn's 'Farewell' Symphony and the Idea of Classical Style: ThroughComposition and Cyclic Integration in His Instrumental Music. Cambridge: Cambridge University Press

Wingenbach, T. S., Brosnan, M., Pfaltz, M. C., Peyk, P., \& Ashwin, C. (2020). perception of Discrete emotions in others: evidence for Distinct facial Mimicry patterns. Scientific reports, 10(1), 1-13.

Zbikowski, L. (2002). Conceptualizing Music: Cognitive Structure, Theory, and Analysis. New York: Oxford University Press 
Figure captions

\begin{tabular}{|c|c|c|c|c|}
\hline \multicolumn{2}{|l|}{ Work } & $\begin{array}{l}\text { Ludwig van Beethoven } \\
\text { String Quintet in C minor op. } 104\end{array}$ & $\begin{array}{l}\text { Brett Dean } \\
\text { 'Epitaphs' }\end{array}$ & $\begin{array}{l}\text { Johannes Brahms } \\
\text { String Quintet No. } 2 \text { in G major, op. } 111\end{array}$ \\
\hline \multicolumn{2}{|c|}{ Stylistic period, date of composition } & Classical (1817) & Contemporary (2010) & Romantic (1890) \\
\hline \multicolumn{2}{|l|}{ Overall musical form } & Sonata form & Suite & Sonata form \\
\hline \multicolumn{2}{|l|}{ Movements } & & & \\
\hline \multirow{5}{*}{$\begin{array}{l}\text { Title or tempo description } \\
\text { Musical charactcristics } \\
\text { (tonality and key area, } \\
\text { meter, timbre, etc.) }\end{array}$} & 1 & $\begin{array}{l}\text { Allegro con brio } \\
\text { C minor - tonic } \\
3 / 4\end{array}$ & $\begin{array}{l}\text { 'Only I will know'. } \\
\text { Gently flowing, with intimate intensity. } \\
4 / 4 \text { infused by } 5 / 8 \text { and } 6 / 8 \text {. Unique } \\
\text { texture through the use of overtones and } \\
\text { bowing techniques. }\end{array}$ & $\begin{array}{l}\text { Allegro non troppo, ma con brio } \\
\text { G major - tonic } \\
9 / 8\end{array}$ \\
\hline & 2 & $\begin{array}{l}\text { Andante cantabile con variazioni } \\
\text { E-flat major - non-tonic } \\
\text { 2/4 }\end{array}$ & $\begin{array}{l}\text { 'Walk a little way with me'. Moderato } \\
\text { scorrevole. * } \\
\text { Subscquent sections with varying metcr } \\
\text { and tempo. }\end{array}$ & $\begin{array}{l}\text { Adagio } \\
\text { D minor-non-tonic } \\
2 / 4\end{array}$ \\
\hline & 3 & $\begin{array}{l}\text { Menuetto Quasi allegro } \\
\mathrm{C} \text { minor (Trio in } \mathrm{C} \text { major) - tonic } \\
3 / 4\end{array}$ & $\begin{array}{l}\text { 'The philosopher'. Quasi cadenza - } \\
\text { suddenly flowing and floating. } \\
\text { No meter in the beginning, then steady } \\
\text { pulse, no clear pulse in the end. }\end{array}$ & $\begin{array}{l}\text { Un poco allegretto } \\
\mathrm{G} \text { minor (Trio in } \mathrm{G} \text { major) - non-tonic } \\
3 / 4\end{array}$ \\
\hline & 4 & $\begin{array}{l}\text { Finale. Prestissimo } \\
\text { C minor - tonic } \\
2 / 2\end{array}$ & $\begin{array}{l}\text { 'György meets the Girl Photographer'. } \\
\text { Fresh, energetic. } \\
\text { Steady pulse of } 1 / 16 \text { notes with changing } \\
\text { accents, cngaging rhythm. }\end{array}$ & $\begin{array}{l}\text { Vivace ma non troppo presto - Animato } \\
\text { G major - tonic } \\
2 / 4\end{array}$ \\
\hline & 5 & & (not presented in the concert) & \\
\hline
\end{tabular}

Figure 1. Program and description of the works. * Presented via loudspeakers. The term 'work' describes the specific performance of that piece as experienced by the participants of the current study.
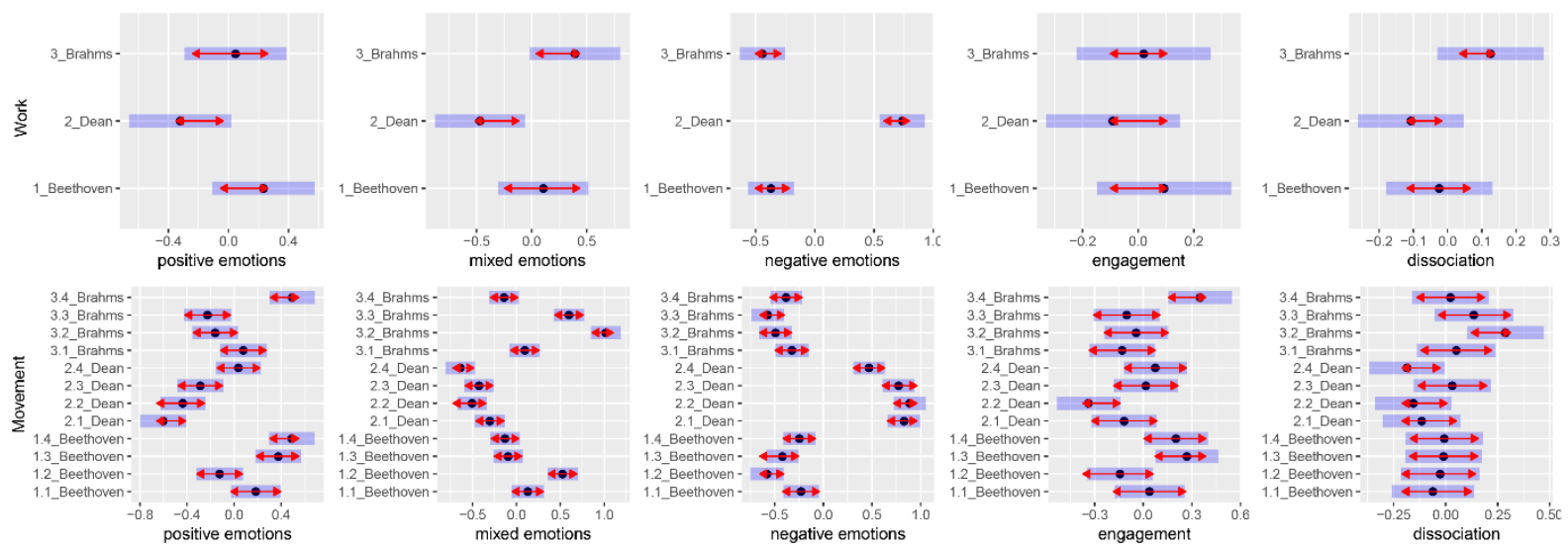

Figure 2. Differences (estimated marginal means) between musical works (upper row) and movements (lower row) in emotion and absorption ratings (latent variables). Pairwise comparisons with mean (black circle), 95\% confidence intervals (CIs; blue (light grey) bars) and "emmeans" statistics depicting the significance of comparisons (overlapping red (dark grey) arrows mean no differences). 

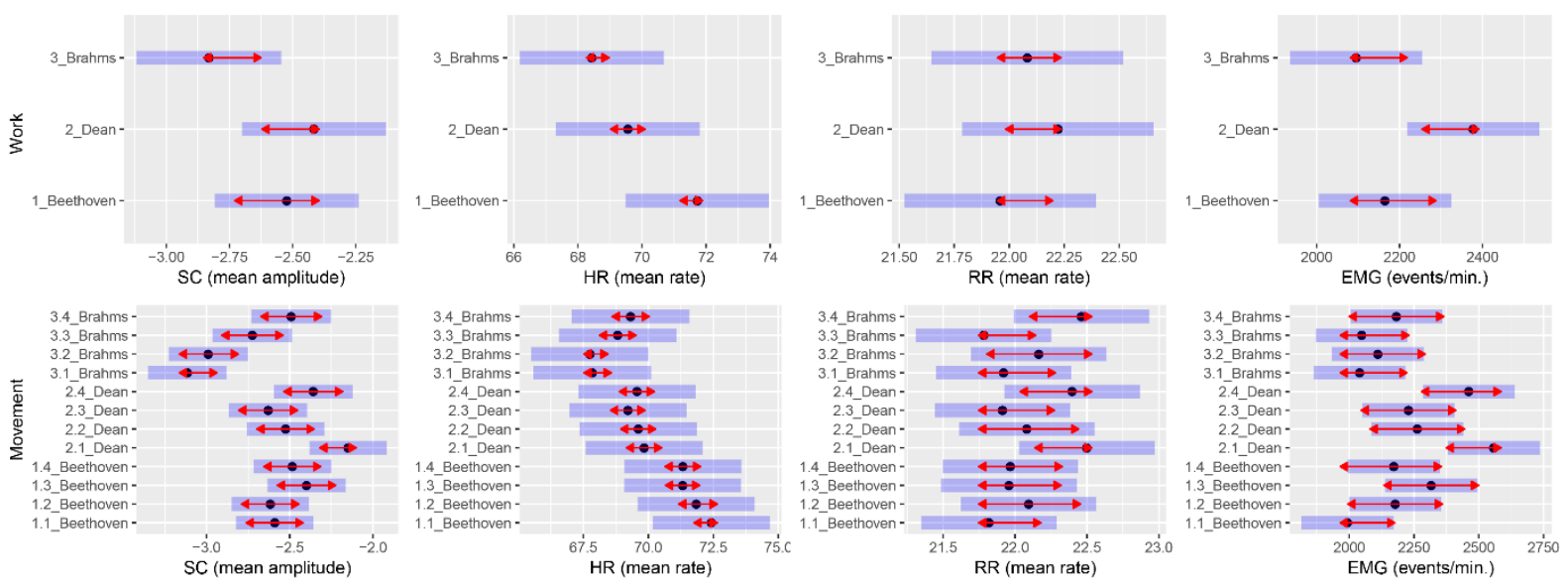

Figure 3. Differences between works (top row) and movements (bottom row) in psychophysiological measures; for details see Figure 2 . 
SC

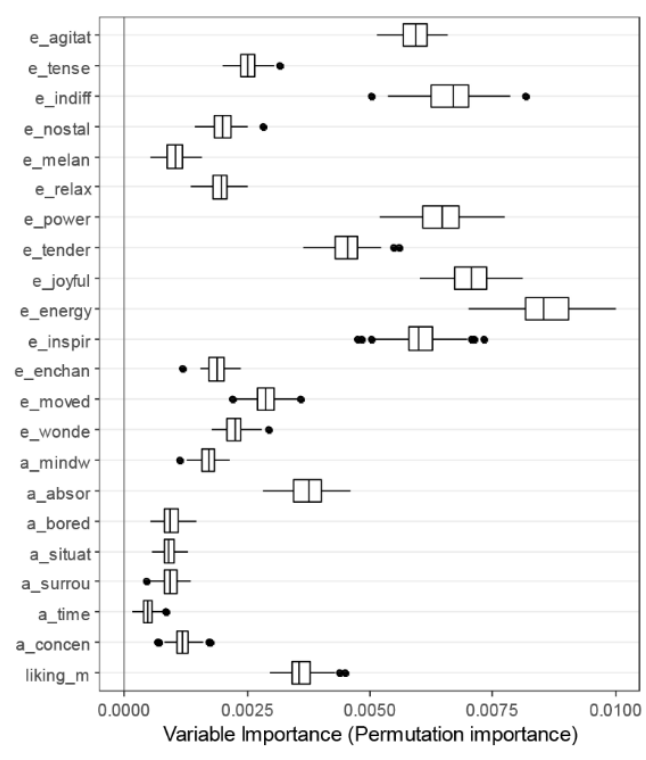

RR

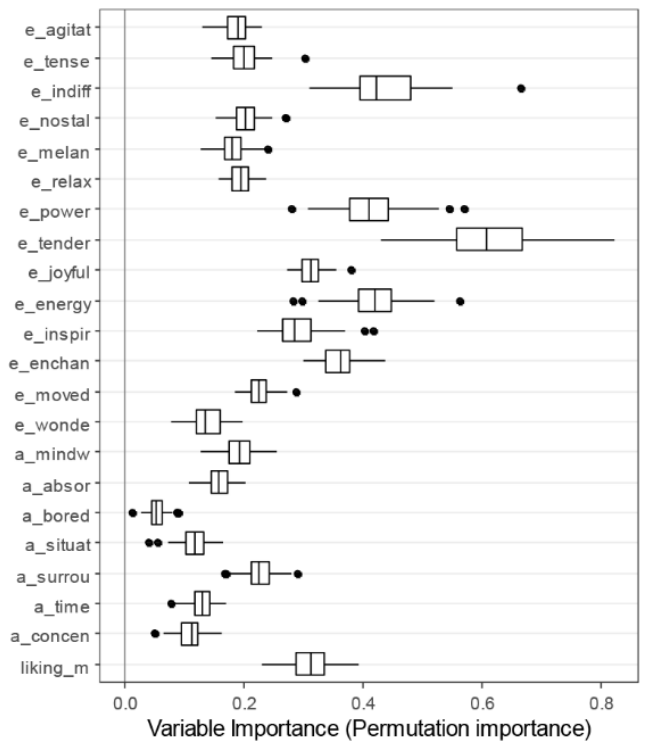

$\mathrm{HR}$

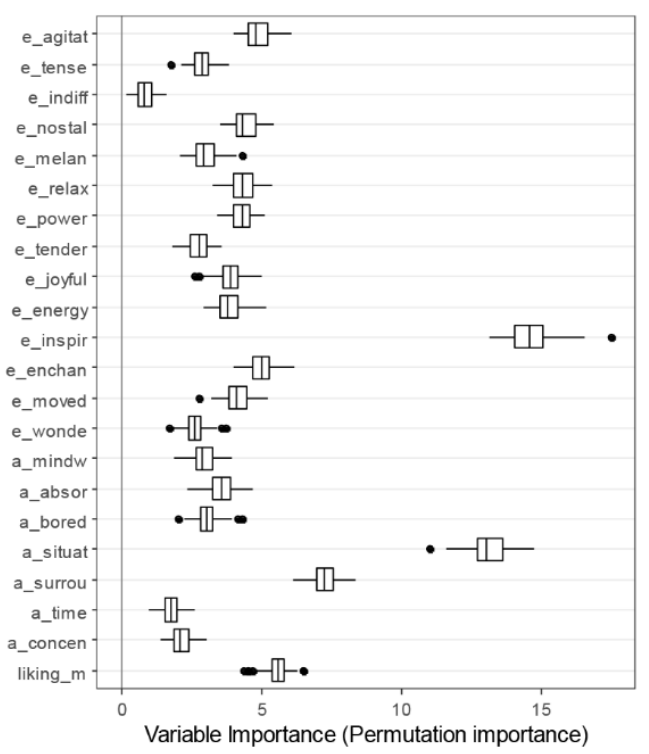

EMG

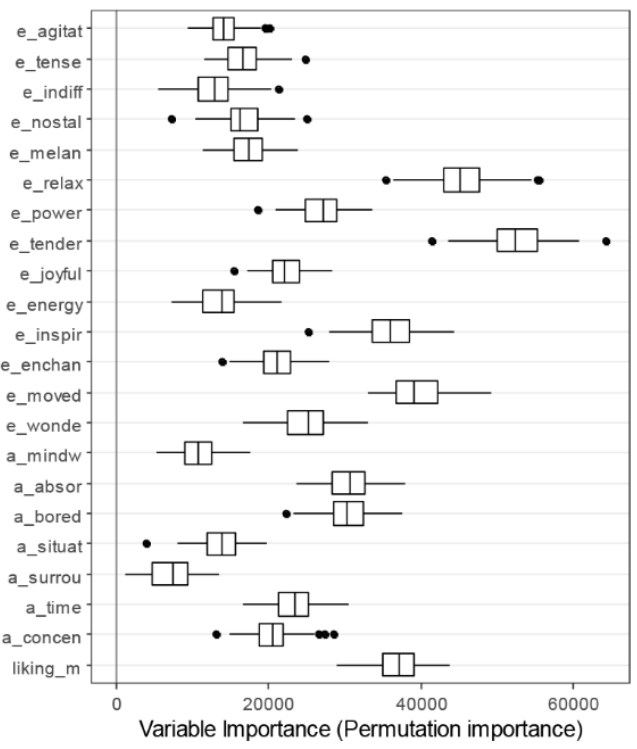

Figure 4. Importance values $(\%$ IncMSE $=$ percent increase in mean squared error of predictions; values in their original units) for each emotion and absorption item and physiological measure. "e_"= GEMIAC, “a_" = absorption scale, “_m” = liking rating per movement. 


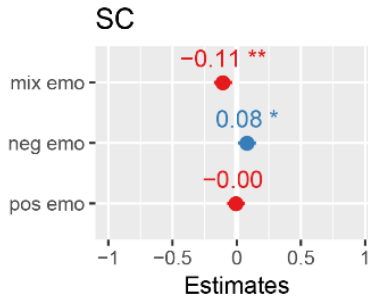

$\mathrm{SC}$

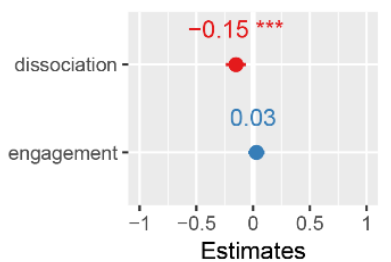

$\mathrm{HR}$

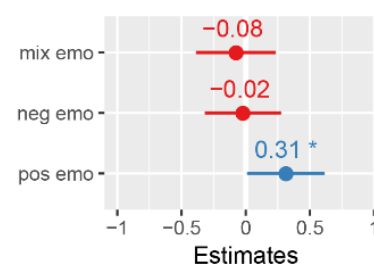

HR

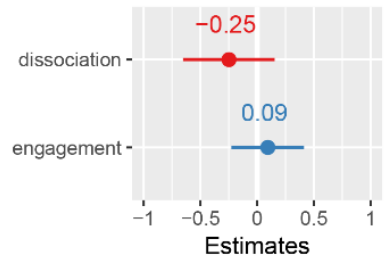

RR

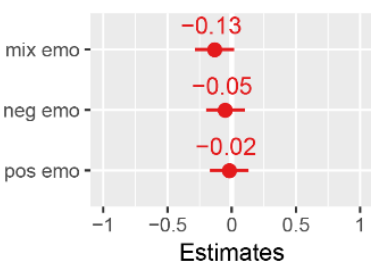

RR

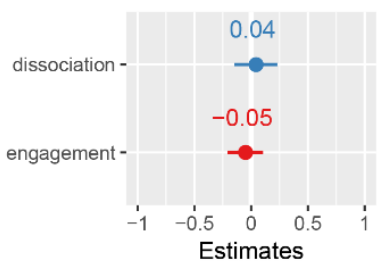

EMG

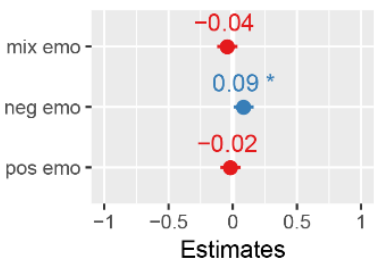

EMG

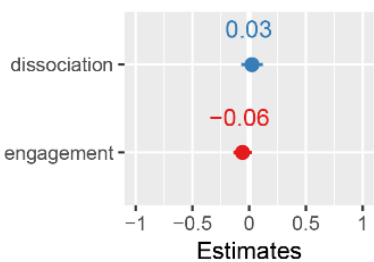

Figure 5. Beta estimates from the linear mixed effects models for all latent variables. ${ }^{* * *} p<$ $.001, * * p<.01, * p<.05$.

\begin{tabular}{|c|c|c|c|c|c|c|c|c|}
\hline \multirow{2}{*}{ 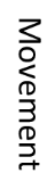 } & \multicolumn{3}{|c|}{ Classical - Beethoven } & \multirow{2}{*}{ Section } & \multicolumn{3}{|c|}{ Romantic-Brahms } & \multirow{2}{*}{ 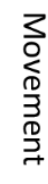 } \\
\hline & Physiology & $\begin{array}{l}\text { Emotions } \\
\text { Absorption }\end{array}$ & $\begin{array}{c}\text { Tonal } \\
\text { structure }\end{array}$ & & $\begin{array}{c}\text { Tonal } \\
\text { structure }\end{array}$ & $\begin{array}{l}\text { Emotions } \\
\text { Absorption }\end{array}$ & Physiology & \\
\hline 1 & & & tonic & opening & tonic & & - HR, - SC & 1 \\
\hline 2 & & mixed & nontonic & \multirow{2}{*}{ inner } & nontonic & mixed & & 2 \\
\hline 3 & (+ EMG) & $\begin{array}{c}\text { positive, } \\
\text { engagement }\end{array}$ & tonic & & nontonic & mixed & & 3 \\
\hline 4 & & positive & tonic & closing & tonic & $\begin{array}{c}\text { positive, } \\
\text { engagement }\end{array}$ & $+H R,+S C$ & 4 \\
\hline
\end{tabular}

Figure 6. Grouping of movements in the classical and the romantic works. 